\title{
Synthetic rope responses in the context of load history: The influence of aging
}

\author{
Weller Samuel ${ }^{1,{ }^{*}}$, Davies Peter ${ }^{2}$, Vickers A. W. ${ }^{1}$, Johanning L. ${ }^{1}$ \\ ${ }^{1}$ Univ Exeter, Coll Engn Math \& Phys Sci, Renewable Energy, Penryn, Cornwall, England. \\ 2 IFREMER, Ctr Bretagne, Marine Struct Lab, Bretagne, France. \\ * Corresponding author : Samuel Weller, email address : S.Weller@exeter.ac.uk
}

\begin{abstract}
:
In order to design marine renewable energy mooring systems which are both economical and durable it is necessary to establish the lifecycle performance of individual components. In parallel with numerical tool development, physical component testing utilising realistic load cases is pivotal in achieving a greater understanding of performance variations including the contribution of degradation mechanisms. Building upon previous experimental tests conducted by the authors, tension-tension tests were conducted on a sample used in first part of the study and samples extracted from a mooring line which was deployed for 18 months with the South West Mooring Test Facility. In agreement with the first part of the study it was found that sample axial stiffness and damping are influenced by load history and instantaneous strain. The increased compliance, lower load bearing capacity and reduced tensiontension fatigue performance of aged specimens are symptomatic of fibre-on-fibre abrasion damage sustained in service. Visual inspections of the rope and yarns including scanning electron microscope analysis of fibres revealed that abrasion wear was accelerated by debris found within the rope structure, highlighting the importance of preventing particle ingress. Datasets are provided to facilitate the development of rope and mooring system simulation tools.
\end{abstract}




\section{Graphical abstract}

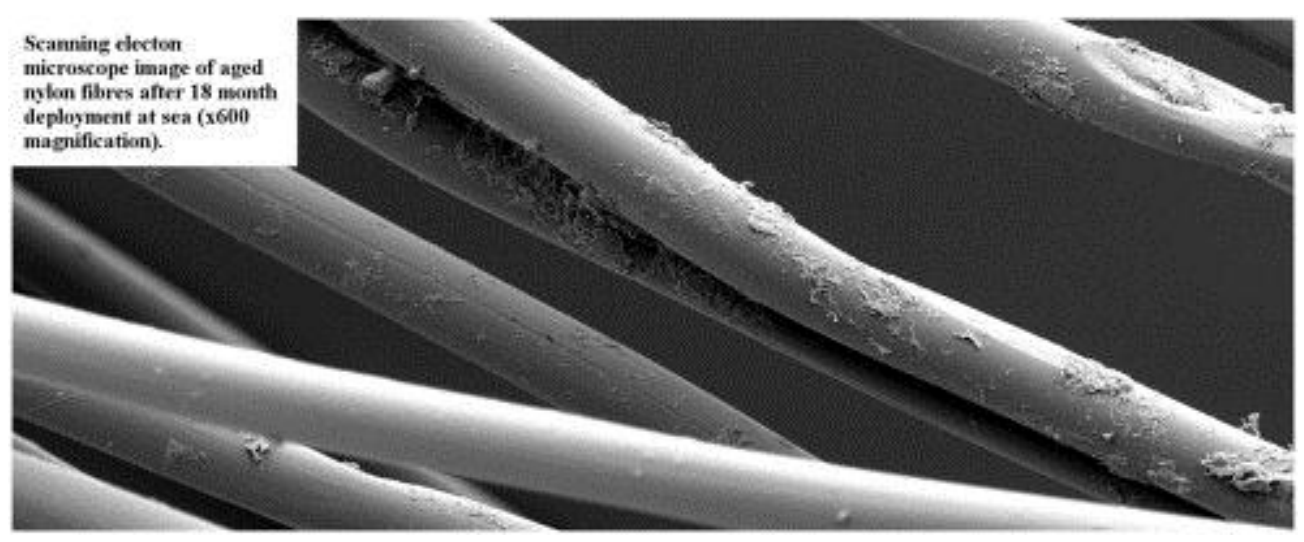

\section{Highlights}

Dynamic tension experiments are reported for new and aged nylon mooring rope samples. Instantaneous rope properties are dependent on the applied load history. Performance and damage of aged samples deployed at sea for 18 months are assessed. Axial stiffness and durability are significantly reduced for the aged samples. To facilitate numerical tool development, supplementary data files are included.

Keywords: Synthetic mooring rope, Nylon, Marine renewable energy (MRE) device, Load history, Operational and long-term performance, Damage

\section{Introduction}

\subsection{Synthetic mooring ropes for marine renewable energy (MRE) mooring systems}

The Carbon Trust Technology Innovation Needs Assessment (TINA): Marine Energy Summary Report [32] reported that the Cost of Energy of mooring and foundations for wave and tidal energy devices is approximately $10 \%$. Paredes et al. in [40] highlighted the disparity between the cost of mooring systems for floating oil and gas platforms and MRE devices in respect to the total expenditure of the system and profit obtained from the sale of the product. This is in part due to the current necessity of MRE mooring designs to adhere to existing offshore guidelines and component testing procedures (e.g. [11, 19, 18, 7]) which 
have questionable relevance for MRE devices. To facilitate the design of economical mooring systems, more relevant design standards such as the forthcoming IEC TC114 guidelines [26] are in development. The utilisation of synthetic ropes instead of mooring chains or wires has been identified as one way of reducing the capital cost of MRE mooring systems (e.g. [8]) due to their comparatively low unit cost, as quantified by Ridge et al. in [42]. In addition, the low weight per unit length of these components and inherent ability to absorb tensile energy (and hence reduce peak loads) enable lower capacity connecting hardware and more efficient device structures to be specified. Over the past two decades these advantages have driven a transition towards polyester, nylon, HMPE and aramid mooring ropes to be utilised for the station-keeping of offshore equipment. In addition a notable number of permanent mooring system failures have been caused the failure of steel components [36, 33]. The shift to synthetic ropes has initiated large scale research and development (R\&D) programs including physical testing and the development of numerical codes to model rope behaviour [14, 24, 9, 31, 39, 37]. Significant progress has been made in understanding the operational and long-term performance of these components in the context of the loads experienced by offshore equipment mooring lines. One such material, polyamide (nylon) has been favoured for demanding applications (e.g. SPM hawsers [24]) and its compliance, low unit cost and weight mean that it is a feasible contender for MRE mooring systems [42].

\subsection{Aging mechanisms}

Due to their prevalent use in the offshore industry the damage mechanisms which reduce the load carrying capacity of synthetic ropes have been well studied $[6,5,23,30,42,35]$ including, but not limited to: creep, ultraviolet (UV) exposure, tension and compression fatigue (through load cycling), external abrasion, wet-dry cycling, hysteresis heating and snatch loading.

Synthetic ropes gradually extend or creep under the application of continuous tensile loading [15] and considerable effort has been put into improving the creep characteristics of materials which are susceptible to this phenomenon [45]. For large platforms such as those used in the oil and gas sector, mooring lines are usually retensioned in order to retain the stiffness of the mooring system [36]. Ropes constructed from polyolefin materials (i.e. polyethylene and polypropylene) are particularly susceptible to degradation through exposure to UV light. In the context of operational conditions experienced by mooring ropes, fatigue induced by load cycling occurs in two modes: i) tension-tension and ii) compression loading. Tension-tension fatigue is mainly caused by wear occurring due to friction between moving fibres or yarns which are in contact [23]. This wear can be accelerated by the ingress of debris such as grit or marine species into the rope structure [4]. Compression fatigue occurs when fibres of stiff materials (i.e. aramid) buckle and fatigue concentrations or 'hinges' are formed through repeated loading [35]. External abrasion to the outer elements of the rope may also occur. It is possible for salt crystals to form during wetting and drying cycles if the rope is partially submerged and this could form an abrasive medium contributing to wear between contacting fibres [5]. The hysteretic response of viscoelastic materials in combination with slip occurring between fibres will cause localised heating of the rope. Research has demonstrated that in extreme cases (such as large diameter polyester ropes subjected to large strain ranges) 
heating can cause peeling and melting of the fibre surfaces [23, 39]. The snatch loading of ropes attached to a highly dynamic MRE device may also cause localised heating. However the snatch loading of synthetic materials has been well studied for other applications (e.g. aircraft arresting systems, [34]) and provided that the load capacity of the rope is not exceeded and the dissipation of heat to the exterior of the rope is sufficient, occasional snatch loading should not result in damage. Offshore experience and laboratory testing has led to the development of friction reducing fibre coatings (known as 'marine finishes') to improve yarn-on-yarn abrasion performance and micron-level particle filtration screens to prevent the ingress of potentially abrasive debris [27]. Braided jackets surrounding the load bearing elements of the rope are also used to prevent degradation through external abrasion or UV exposure. These three developments have contributed to significant increases in the fatigue performance of synthetic ropes $[42,38]$.

\subsection{Component testing}

Despite the accumulated knowledge of the offshore sector the performance and long-term durability of these materials is not fully understood for MRE applications, which are likely to include highly variable loading conditions. In addition the need to achieve a Levelized Cost of Energy which is competitive with other forms of electricity generation may require the adoption of a less conservative approach to mooring system design. Carbon Trust-funded studies focusing on MRE devices such as [42] and [43] have paved the way to the development of a knowledge base. However further detailed component testing and the continued development of performance and reliability tools are required to inform the design, operation, maintenance and retirement of economical and durable MRE mooring systems.

In an earlier performance assessment conducted by the authors [47] as part of the MERiFIC (Marine Energy in Far Peripheral and Island Communities) consortium, three dry, new, parallel-stranded nylon 6 rope samples were subjected to loading conditions that are potentially relevant to those experienced by buoy-like MRE devices or other small offshore equipment. By varying the initial loading conditions (through different levels of 'bedding-in' cycling) both non-linear and time-dependent behaviour were demonstrated; more specifically the instantaneous level of strain had a direct influence on the subsequent axial stiffness and damping of each sample. This trend was also observed after the application of a load set comprising a mixture of harmonic and irregular loading intervals, with the irregular time-series based on axial mooring tension measurements recorded by the University of Exeter's South West Mooring Test Facility (SWMTF: [29]). Utilising the measurements obtained in the first part of this study, it is the intention of the second part to gain insight into the effect of rope saturation, by retesting Sample 2 from the previous study (NS2) after prolonged submersion in tap water. Comparisons are also made between the load-to-failure strain behaviour of two new samples (NS5 and NS6) after submersion in tap and sea water and a dry sample (NS4). This analysis is extended further to investigate the effects of aging with comparisons made between the performance of rope sample NS2 and one extracted from the SWMTF mooring rope after its first deployment at sea (AS1). In addition, investigations are made 
into the performance of aged and new yarn assemblies subjected to scaled (by tenacity, units: N/Tex) harmonic loading, as well as the tension-tension fatigue performance of new and aged yarns.

In the next section the experimental equipment used in this study is outlined. The loading regimes applied to the rope samples are then defined in the context of mooring tension measurements recorded by the SWMTF. The experimental method and analysis techniques adopted are then summarised. In Section 3 results are presented from load tests involving new and aged rope and yarn assemblies (including yarn assemblies loaded until failure). In Section 4 tests involving harmonic, irregular and failure loading of rope samples in dry and wet states are presented. In Section 5 possible damage mechanisms are assessed utilising visual inspection tests as well as yarn-on-yarn abrasion tests to determine the fatigue performance of new and aged yarns.

\section{Experimental approach}

In this section the experimental equipment and analysis method adopted are summarised. For further details the reader is referred to a more detailed description in the first part of the study [47].

\subsection{Rope and yarn samples and the South West Mooring Test Facility (SWMTF)}

The ropes tested in this study comprise multi-filament nylon 6 fibres organised in hierarchical levels of yarns, yarn assemblies, strands and seven parallelstranded subropes covered by a protective non-load-bearing jacket (Figure 1a). In this construction six outer subropes surround a single central subrope. A filter layer was not present in this construction. New samples NS2, NS4, NS5 and NS6 were supplied by the manufacturer pre-spliced with an eye-to-eye distance of approximately $5 \mathrm{~m}$. This rope construction was also used for the upper $20 \mathrm{~m}$ of the three catenary mooring lines used on the SWMTF (Figure 1b and [29]). In order to gain insight into the influence of aging on rope condition and material properties, an aged rope sample (AS1) was extracted from one of the three mooring lines used during the first 18 month long deployment of the SWMTF. Upon rope recovery a significant amount of bio-fouling, mainly consisting of kelp and mussel growth was evident, to the extent that the outer rope diameter increased from $D=0.044 \mathrm{~m}$ to approximately $0.15 \mathrm{~m}$ (Figure 1c). Marine growth of this magnitude will clearly increase the submerged mass and drag of the line [19] and subsequently affect the dynamic response of the mooring system and attached surface equipment. Growth on the outer jacket was removed prior to division of the rope into three sections. For this study a $4.5 \mathrm{~m}$ long sample was taken from the SWMTF rope with the original splice and eye retained at one end and three u-bolts used to terminate the other end. A second sample was taken from the SWMTF rope and used for preliminary tests at L'Institut français de recherche pour l'exploitation de la mer (IFREMER) and the University of Exeter [44]. Yarn assemblies, yarns and fibres were extracted from the remaining central portion of the SWMTF rope for detailed analysis and testing. 


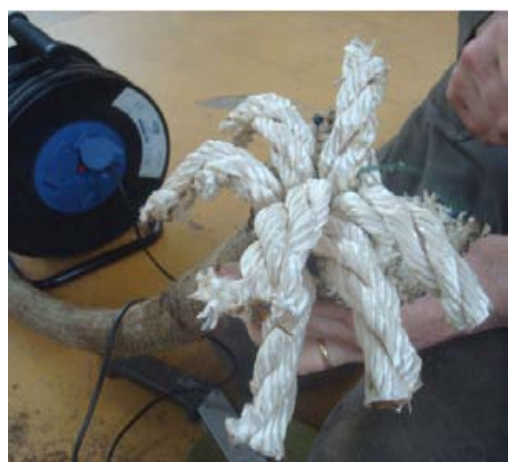

(a)

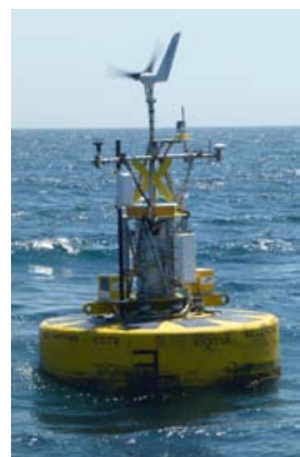

(b)

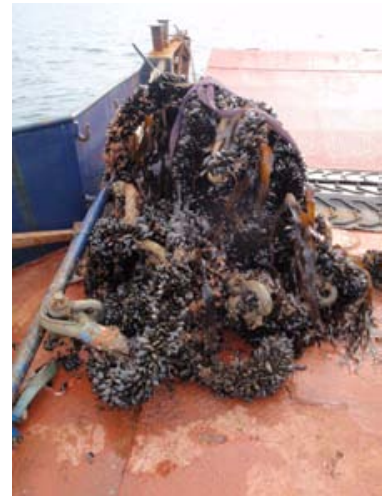

(c)

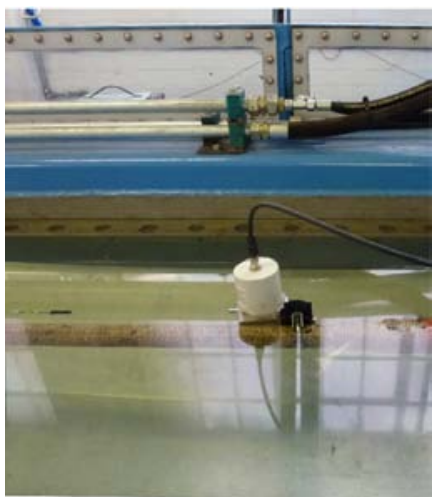

(e)

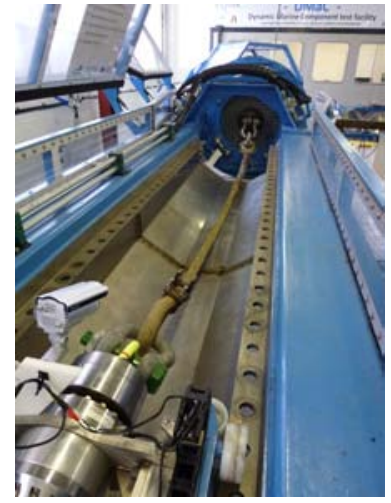

(d)

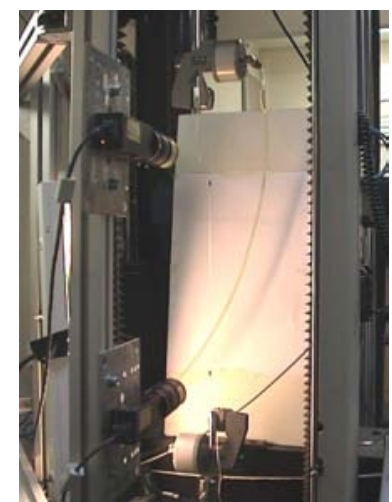

(f)

Figure 1: a) Aged rope sample with outer jacket removed showing parallel-strand construction. b) SWMTF moored in Falmouth Bay. c) Recovered SWMTF mooring rope showing extensive kelp and mussel bio-fouling. d) DMaC test facility. e) Draw-wire transducer clamped to submerged aged sample AS1 at DMaC.f) INSTRON machine with video-extensometry system 


\subsection{Rope testing procedures}

In a dry state the two rope samples (NS2 and AS1) were subjected to the dynamic load set 'LS1' (defined in Table 1) utilising the 100 Tonne hydraulic test machine at IFREMER. The sequence commenced with 10x cycles of bedding-in with the maximum load applied equivalent to $20 \%$ of the minimum break load (MBL) of the rope as specified by the manufacturer $(466 \mathrm{kN})$. Bedding-in is a standard test procedure (e.g. [37]) to stabilise the properties of the rope following manufacture and enable the rope to be tested at a known initial state. The bedding-in cycles were followed by a single unload/load cycle and an interval of harmonic loading (load level A) at a constant load amplitude $(10.7 \mathrm{kN})$ and three non-monotonically ordered oscillation periods (50 s, $25 \mathrm{~s}$ and $100 \mathrm{~s}$ ). Following a short interval of $300 \mathrm{~s}$ during which the load was held constant at $2 \mathrm{kN}$, the sequence was repeated for four more load levels (B-E) up to a maximum load of $116.5 \mathrm{kN}$ (25\% MBL; Figure 2a). To determine if the strain achieved during loading was recoverable or residual, the load was then held constant for $1 \mathrm{~h}$ at $3.5 \mathrm{kN}$ and then $9.8 \mathrm{~h}$ at $2 \mathrm{kN}$ (load levels $\mathrm{F}$ and $\mathrm{G}$ ). The standardised approach of rope testing involving many hundreds (or thousands) of harmonic load cycles $[42,37]$ may not be directly applicable for small offshore equipment deployed in highly dynamic environments (i.e. MRE devices) due to the temporal response behaviour of synthetic ropes resulting from non-linear material and structural processes [22]. Given that these processes are poorly understood in the context of the highly dynamic mooring loads, the rope samples were also subjected to load set 'LS3' in wet and dry states utilising the DMaC (Dynamic Marine Component) test facility at the University of Exeter (Figure 1d). The harmonic loading intervals in this load set incorporate mean axial mooring tensions and oscillation periods which are characteristic to those measured by the SWMTF. Harmonic oscillation periods up to $100 \mathrm{~s}$ were also included for comparison with existing studies focused on mooring line loading due to slow drift. To extend the standard approach of repeated harmonic loading, load set LS3 also included two 30 min representations (load levels $\mathrm{R}$ and $\mathrm{S}$ ) of axial mooring line tensions recorded by the SWMTF in calm and mild-storm conditions [46, 47] (Figure 2b). During these intervals the average tensions for Lines 1-3 were $3.77 \mathrm{kN}$ and 5.97 $\mathrm{kN}$ respectively (equivalent to $0.8 \% \mathrm{MBL}$ and $1.28 \% \mathrm{MBL}$ ), with intermittent snatch loads recorded throughout the first SWMTF deployment (e.g. ranging from 0 to $52.2 \mathrm{kN}$ or 0 to $11.2 \% \mathrm{MBL}$ during the mild-storm time-series). These loads are therefore small compared to the MBL specified by the manufacturer. For wet testing at the University of Exeter, the aged and new samples were submerged in tap water (initially measured to be $20{ }^{\circ} \mathrm{C}$ ) for 31 and 32 days respectively prior to fully submerged testing in the $\mathrm{DMaC}$ test facility. It is standard practice to test saturated ropes in tap, rather than salt water [18], partly to mitigate the corrosion of submerged test equipment. Furthermore, it has been demonstrated that nylon exhibits similar fatigue performance in tap and salt water solutions (e.g. as demonstrated for nylon 6.6 fibres by Kenny et al. in [30]). An exception to this generalisation, as previously mentioned, is abrasion caused by salt crystals in ropes subjected to wetting-drying cycles. In this study the soaking period was deemed to be sufficient based on earlier sea water uptake tests conducted on aged rope samples at IFREMER, in which total saturation was achieved after 12 days. 
In order to compare the dynamic and static loading behaviour of this nylon rope construction, an additional three new rope samples (NS4, NS5 and NS6) were loaded-to-failure using the 100 Tonne hydraulic test machine at IFREMER (loading regime defined in Table 1 as load set 'LS4' and illustrated in Figure 2c). Following a single bedding-in cycle up to $40 \% \mathrm{MBL}$ and a short interval of $300 \mathrm{~s}$ during which the load was held constant at $2 \mathrm{kN}$, the samples were loaded at a constant load rate of $1.9 \mathrm{kN} / \mathrm{s}$ until failure occurred (load level $\mathrm{T}$ ). One sample was tested dry (NS4) and two samples were tested wet after submersion for 45 days in tap water (sample: NS5) and sea water (sample: NS6). After submersion, mass increases of approximately $33 \%$ were noted for both samples.

At IFREMER the applied load, piston displacement and extension of the central rope section (over a distance of approximately $1.1 \mathrm{~m}$, at least $0.25 \mathrm{~m}$ clear of the splices and end terminations) of the samples were measured at a sample rate of $2 \mathrm{~Hz}$. Prior to the start of each test, the original length of the central rope section was measured with each sample pretensioned at $2 \mathrm{kN}$. A faster sample rate $(50 \mathrm{~Hz})$ was used at the University of Exeter to provide a suitable measurement resolution for capturing the response of the samples during irregular loading. For the harmonic and irregular load tests, draw-wire transducers clamped to the rope (at IFREMER: ASM Sensors WS10-375-R1L10 and at DMaC: Applied Measurements: WS12-1000-R1K-L10-SBO-M12, Figure 1e) were used to record sample extension, with a low-pass Butterworth filter (cut-off frequency: $0.9 \mathrm{~Hz}$ ) used to remove signal noise. To avoid damage to the draw-wire transducer during the load-to-failure tests, a video-extensometry system (introduced in Section 2.3) was used to measure sample extension for samples NS5 and NS6. The video-extensometry system was not available for the dry sample (NS4) test and therefore extension measurements are only reported for the first bedding-in cycle of this test.

\subsection{Yarn assembly and yarn testing procedures}

In order to distinguish between constructional and material performance effects, three new and three aged yarn assemblies (comprising 24 yarns) were subjected to scaled loading regimes based on load set LS1 using an INSTRON 5566 test machine at IFREMER (Figure 1f). The aged yarn assemblies were carefully extracted from an outer subrope of the recovered SWMTF rope. The load scaling criterion used was tenacity (units: $\mathrm{N} / \mathrm{Tex}$ ), with the rope Tex based on the measured linear mass of seven subropes $\left(9.04 \times 10^{5} \mathrm{~g} / \mathrm{km}\right.$, ignoring the mass of the non load-bearing jacket) and the yarn assembly Tex based on the measured average linear mass of three yarn assembly samples $\left(4.77 \times 10^{3} \mathrm{~g} / \mathrm{km}\right)$. The length of each yarn assembly sample was measured upon application of a reference load based on the outer diameter of the rope and number of yarn assemblies present in the rope construction (totaling 168): $\frac{9.81 \times 10^{6} D^{2}}{1344}$. The application of sinusoidal load intervals was not possible using the test machine, instead a triangular waveform was specified with the same load limits and equivalent oscillation periods (Figure 3). Therefore direct comparison between the time-varying performance of the rope and yarn assembly samples is not possible. Due to test duration 

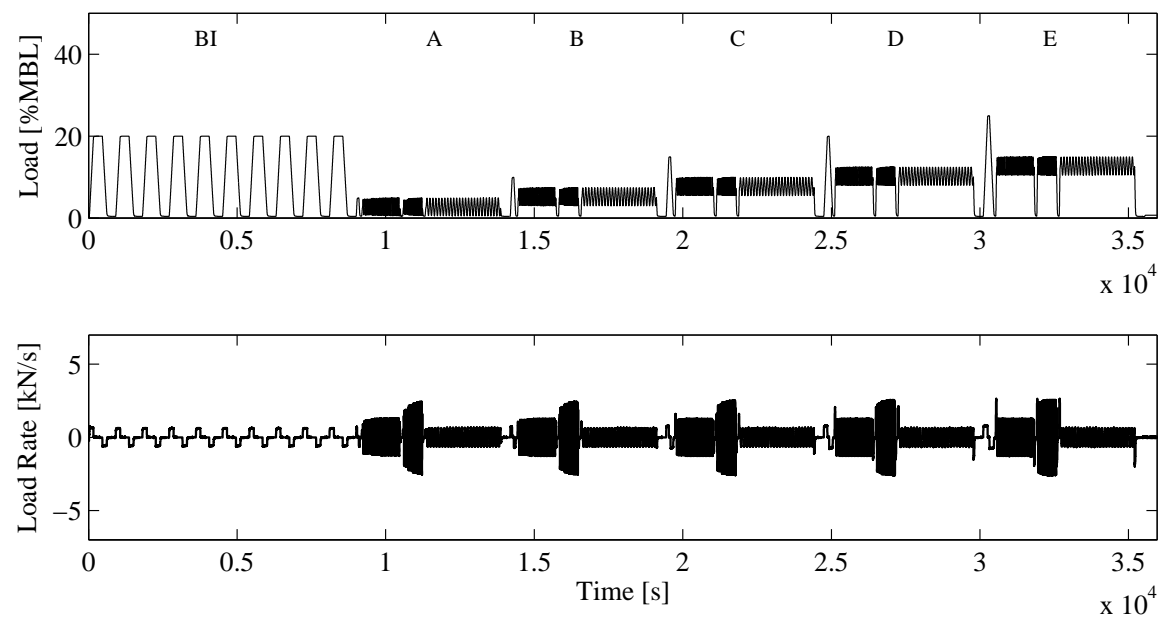

(a)
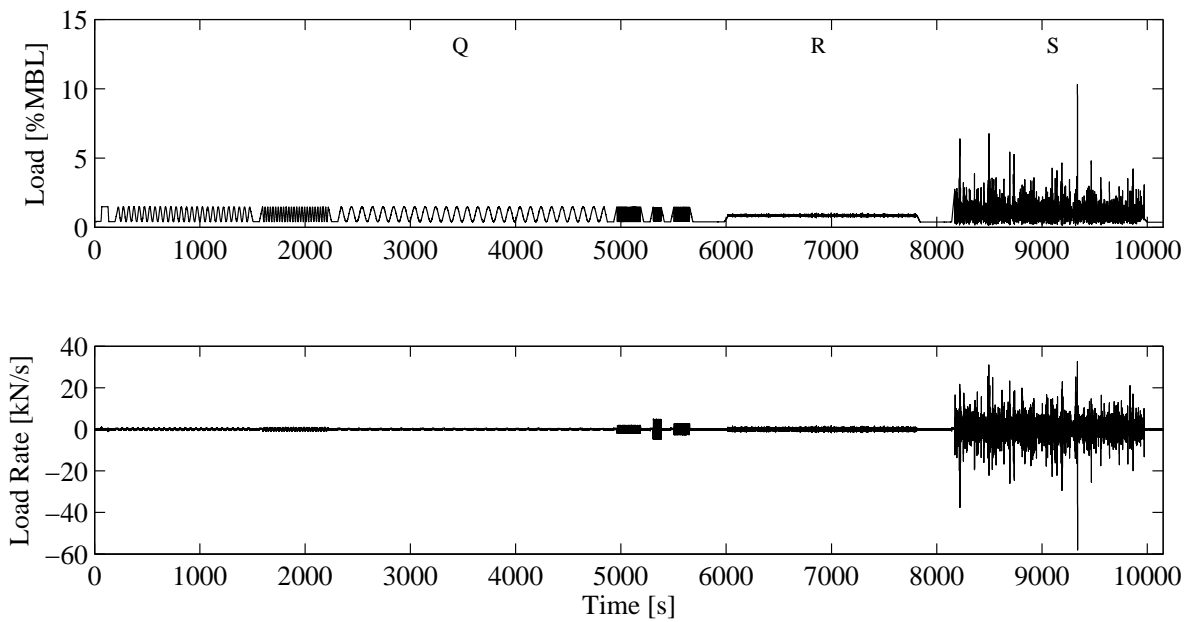

(b)
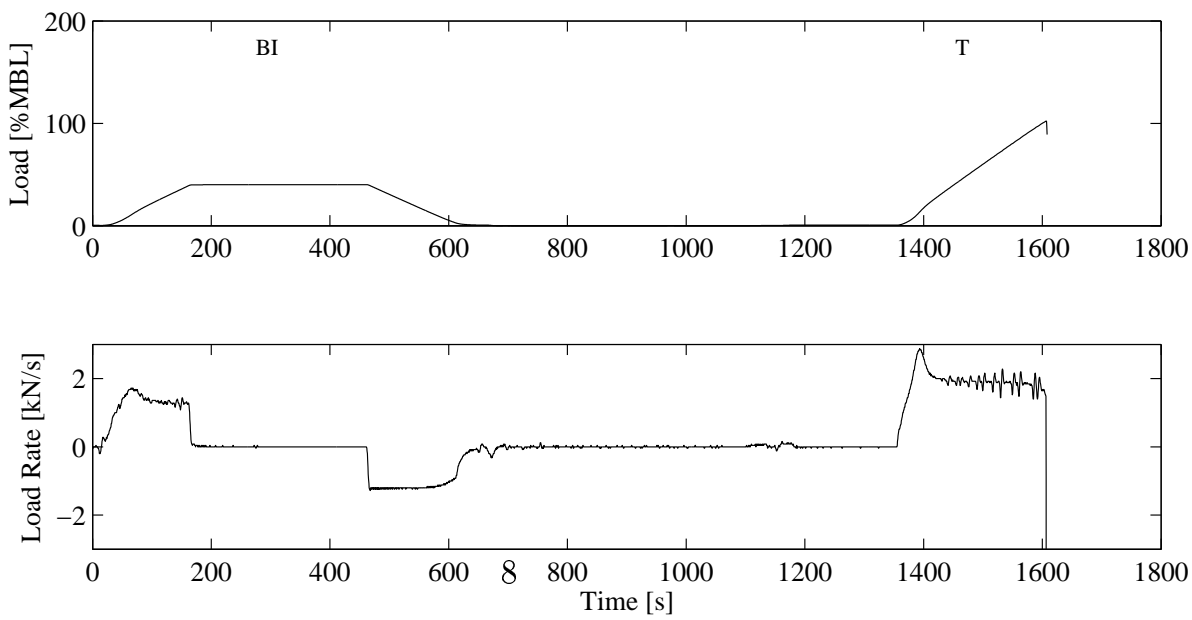

(c)

Figure 2: Measured loads (expressed as a percentage of the rope MBL) and load rate timeseries for the comparison between new and aged rope performance. In a) the first $9.9 \mathrm{~h}$ of load set LS1 are shown, as well as b) the harmonic/irregular loading regime LS3 and (c) load-to-failure test LS4. 


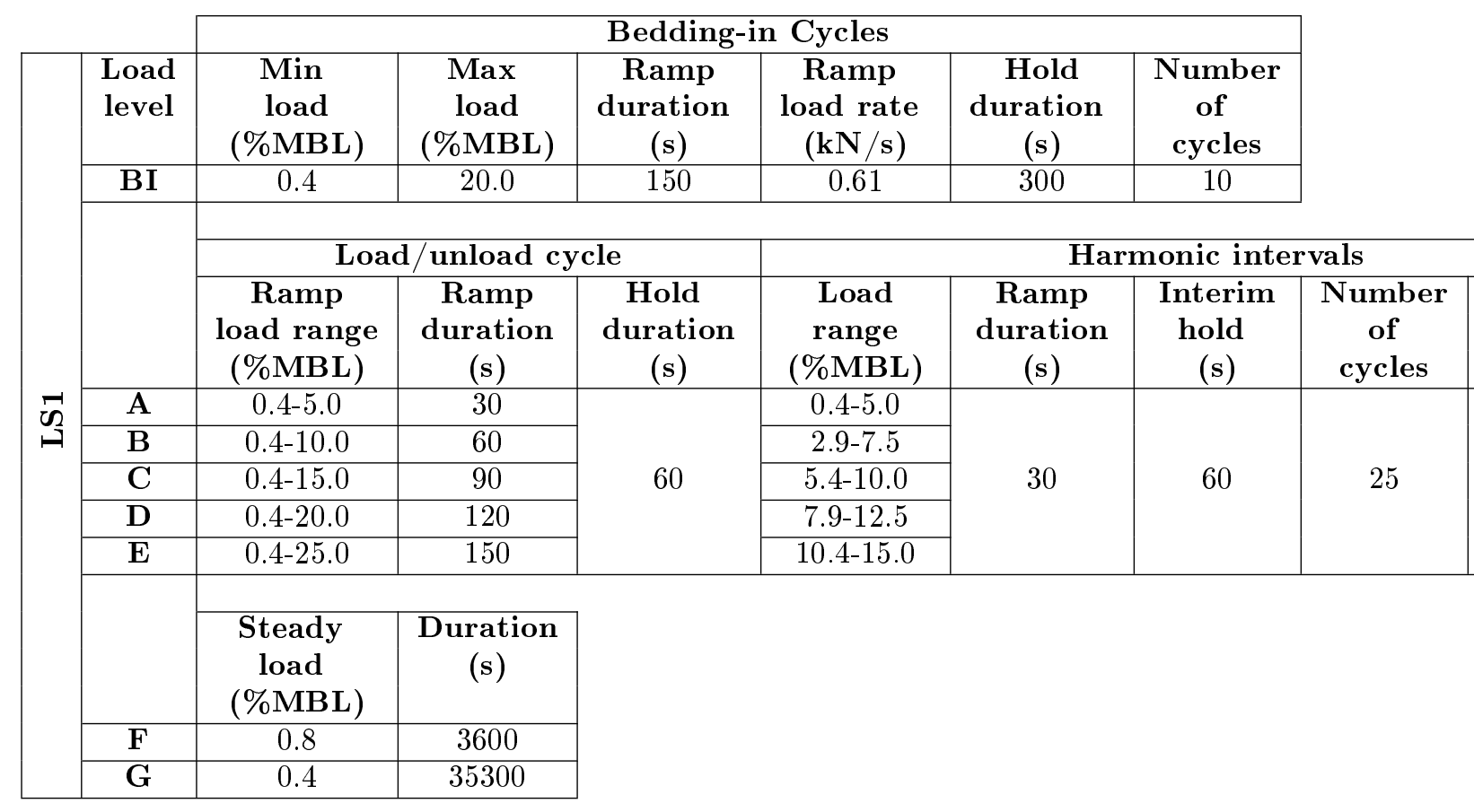

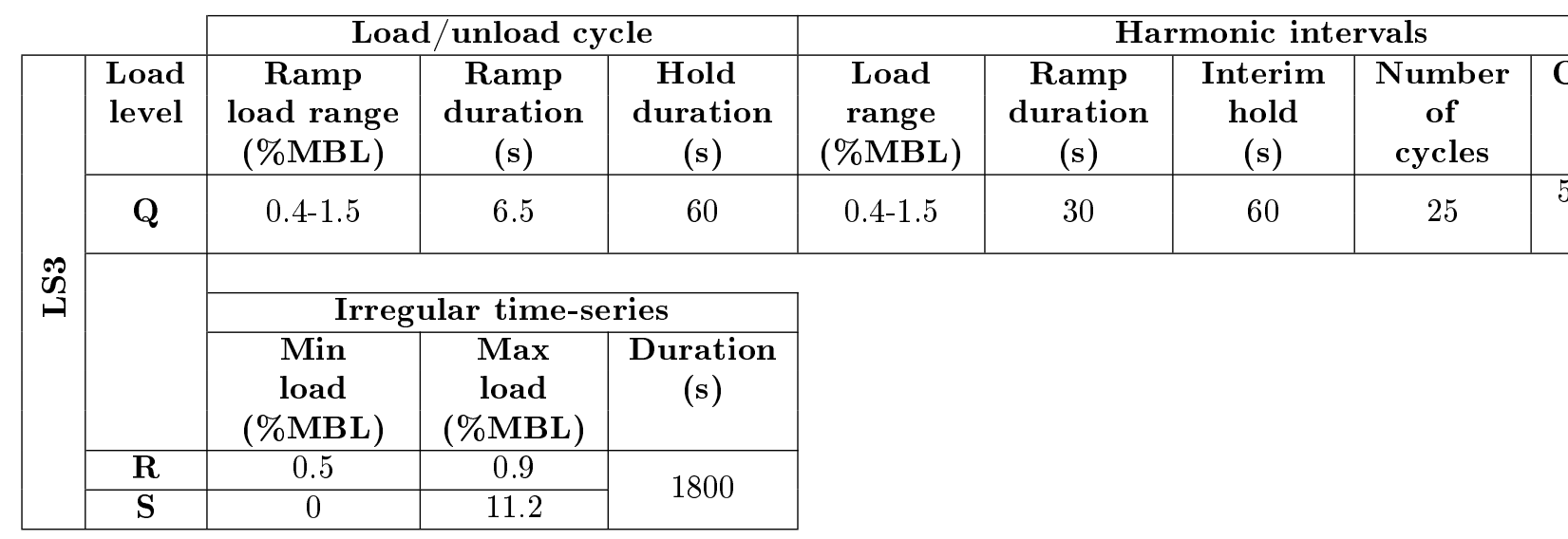

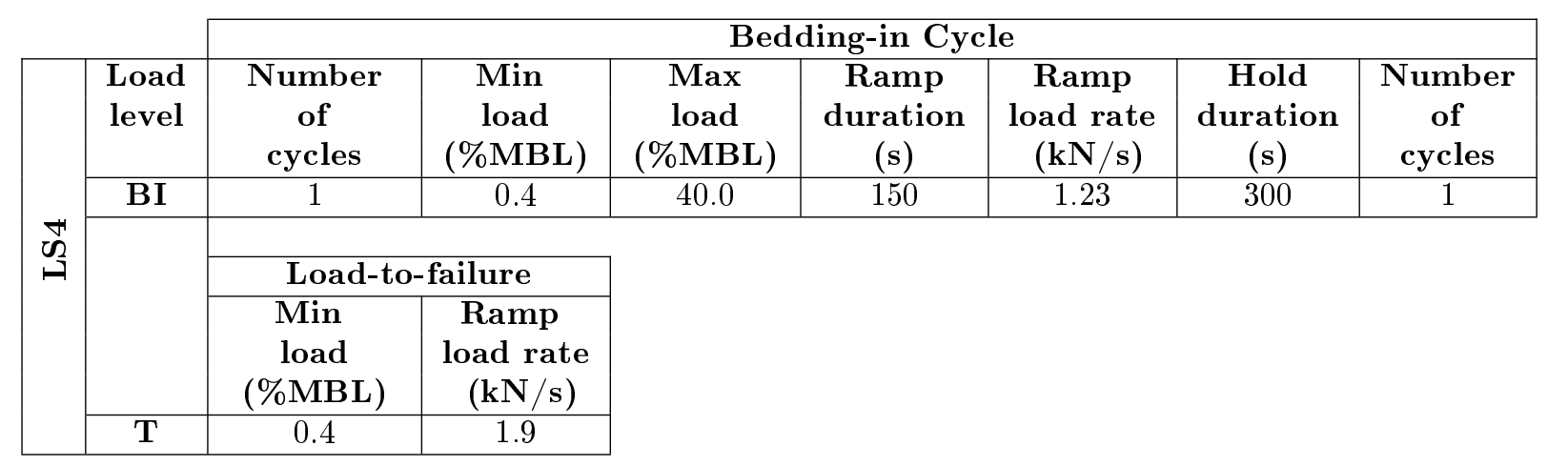

Table 1: Specified loading regimes for the new/aged (LS1 and LS3) and dry/wet (LS3) comparisons. Load-to-failure (LS4) parameters are also listed 
limitations of the equipment, the initial bedding-in cycles of load set LS1 were not included in the scaled loading regimes, furthermore the load level equivalent to $\mathrm{E}$ in Table 1 was conducted as a separate test shortly after the previous load levels. For this reason, all extension and strain calculations reported in this study are based on the length of each yarn assembly measured prior to the start of load level A. Crosshead displacements and applied loads were recorded at a sample rate of $1 \mathrm{~Hz}$. At the same sample rate, extension of the sample was measured using a video-extensometry system developed at IFREMER [25], with the free length of each yarn assembly (approximately $0.41 \mathrm{~m}$ long) defined by black markers bonded to the yarn assembly using cyanoacrylate adhesive (Figure 1f). The resolution of this capture system is dependent on the selected focal range of the two cameras used, which in turn is related to the expected displacement of the markers. Therefore for small displacements a high pixel resolution is possible (average resolution $0.09 \mathrm{~mm} /$ pixel). For large displacements, such as the load-to-failure tests, a wider focal range is required resulting in a slightly lower pixel resolution (average resolution $0.11 \mathrm{~mm} /$ pixel). For this set of results a low-pass Butterworth filter (cut-off frequency: 0.25 Hz) was applied to the measured extension values to remove signal noise.

In order to provide insight into the influence of aging on nylon durability, load-to-failure tests were conducted on an additional 6 yarn assemblies and cycle-to-failure tests were conducted on 32 yarn samples. To compare the load bearing capacity of new and aged yarn assemblies, six samples (three aged and three new) were loaded at a constant load rate of $10.1 \mathrm{~N} / \mathrm{s}$ until failure. In preparing the yarn assemblies, new samples equivalent to those present in the studied rope construction were taken directly from a spool and aged samples were extracted from the central and outer subropes of the SWMTF rope. After applying the black markers for tracking by the video-extensometry system, each yarn assembly was clamped in the INSTRON machine whilst ensuring that the manufactured yarn twist (approximately 1 turn over the free length of the sample) was retained to avoid variations in twist angle which could have influenced the results [35]. In addition, to compare the fatigue performance of new and aged yarns, yarn-on-yarn abrasion tests (using the methodology described in $[3,12]$ and specified in several offshore guidance documents, $[37,1,27,2])$ were carried out on 16 new and 16 aged samples. The abrasion resistance of synthetic fibre ropes such as the one used in this study is particularly sensitive to the marine finish applied to the fibres during rope manufacture [10]. The samples were cycled until failure in natural sea water at four mean tensions ranging between 0.12 and $0.41 \mathrm{~g} / \mathrm{dTex}$. In both the load-to-failure and cycle-to-failure tests aged samples were extracted from the outer sub-ropes of the SWMTF rope, under the presumption that wear would probably be significant in these locations.

\subsection{Measurement analysis procedure}

In this study the sample axial stiffness $(E A)$ for each oscillation cycle is calculated as the gradient of a single degree-of-freedom line fitted to calculated strain $(\varepsilon)$ and measured load $(F)$ values, with strain defined as the ratio of instantaneous extension (measured over the free rope or yarn assembly length) to original length. The start and end of each cycle are defined by calculated strain 
minima. As reported in the previous study [47], the least squares method of linear regression provides a much closer fit to experimental values when compared to the commonly used method of determining axial stiffness [23].

Damping rate, which includes material and structural contributions (such as friction between contacting elements), is calculated using the energy dissipated over each load-unload cycle $\left(E_{d}\right)$, the angular frequency of the oscillation $(\omega)$ and the amplitude of piston displacement $(X)$ [28]. In this calculation the start and end of each cycle are defined by extension $(e)$ minima:

$$
B=\frac{E_{d}}{\pi \omega X^{2}}
$$

Average axial stiffness and damping values are calculated using the last five cycles of each interval for harmonic oscillations. For the irregular loading intervals these values are calculated on a cycle-to-cycle basis. In the latter case it is assumed that each cycle can be treated as an isolated harmonic cycle, with the angular frequency term in Eq. 1 based on the measured time difference between piston displacement minima. Although many of the irregular response cycles are not regular in profile, the damping values calculated using this approach give an indication of sample response during irregular loading. The energy dissipated for hysteresis loops which are fully closed is approximated as the area enclosed within each extension-force loop using trapezoidal integration (Figure 4a)

$$
E_{d}=E_{\text {load }}-E_{\text {unload }}
$$

Partially open hysteresis loops are indicative of temporary or permanent sample extension occurring due to constructional rearrangement and/or material changes (Figure $4 \mathrm{~b}$ ). In this case the integration used to determine energy dissipation is bounded by the cycle start, end and maximum measured elongations $\left(e_{1}, e_{2}\right.$ and $\left.e_{\max }\right)$ as well as the corresponding start and end forces $\left(F_{e_{1}}\right.$ and $\left.F_{e_{2}}\right)$. 


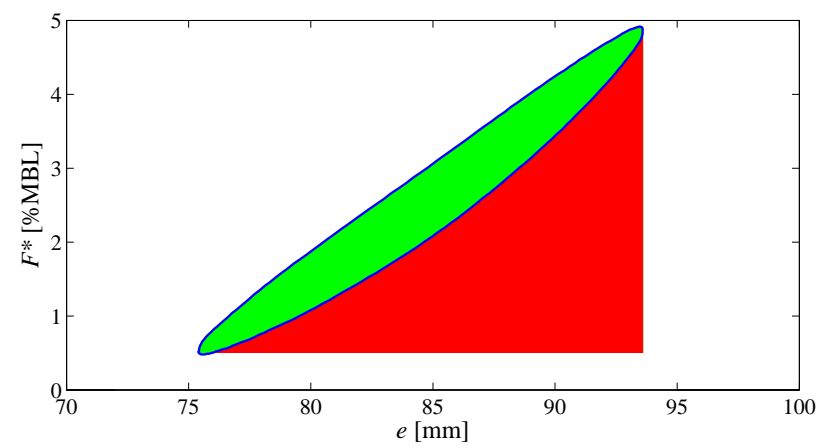

(a)

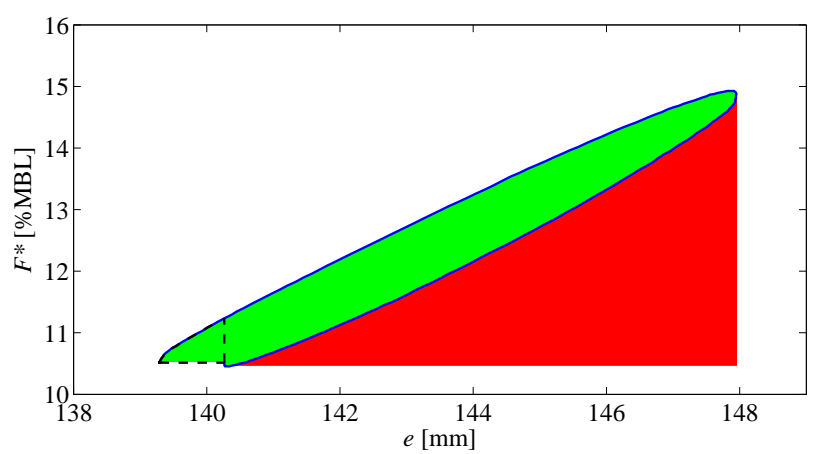

(b)

Figure 4: Examples of a) closed and b) open hysteresis loops for new rope sample NS2 (blue line) showing energy during loading ( $E_{\text {load }}$; green region) and energy during unloading ( $E_{\text {unload }}$; red region). In b) the energy associated with permanent or temporary extension is defined as the area bounded by the dashed line. Measured loads are expressed as a percentage of the rope MBL $(F *=F / M B L)$. (For interpretation of the references to colour in this figure legend, the reader is referred to the online version of this paper.)

\section{Performance of new and aged samples}

In this section the performance of the new and aged rope samples subjected to harmonic and harmonic/irregular loading is compared. Results of tests conducted on new and aged yarn assembly samples are also reported.

\subsection{Harmonic loading}

\subsubsection{Rope samples}

Calculated time-varying strain values are shown in Figure 5 for the aged and new rope samples subjected to LS1, based on alignment of both force timeseries by the minimum force measurement of the first load/unload cycle (at $t=56 \mathrm{~s}$ ). Relevant measurements are contained within datasets 'Inline Supplementary NS2_LS1_Dry' and 'Inline Supplementary AS1_LS1_Dry.txt'. After $10.8 \mathrm{~h}$ of steady loading, residual strain levels were of a similar magnitude to the final bedding-in cycles (aged sample: 6.1\%, new sample: $5.8 \%$ ), suggesting 


\begin{tabular}{|c|c|c|c|}
\cline { 2 - 3 } \multicolumn{1}{c|}{} & \multicolumn{2}{|c|}{ Nylon samples } & \multirow{2}{*}{ Polyester } \\
\cline { 2 - 3 } \multicolumn{1}{c|}{} & New & Aged & \\
\hline$m$ & 0.45 & 0.4 & 0.33 \\
\hline$c$ & 1.55 & 0.98 & 18.5 \\
\hline
\end{tabular}

Table 2: Calculated dynamic stiffness gradient $(m)$ and $y$-intercept $(c)$ values for the two nylon rope samples with values for a parallel strand polyester rope (from [24]) included for reference

permanent (or at least semi-permanent) extension within the time frame of the test procedure. The similar levels of strain achieved after bedding-in suggest that any shrinkage of the aged sample (due to drying out after recovery of the SWMTF rope) would have been 'pulled-out'. Whilst the mean strain levels for both samples are similar, the maximum strain ranges for the aged sample are greater than for the new sample (i.e. aged: $15.4 \%$, new: $14.7 \%$ during bedding-in and aged: $2.2 \%$, new: $1.7 \%$ during harmonic loading). The greater compliance of the aged sample is conducive with broader hysteresis loops (e.g. Figure 6), lower average stiffness values and higher damping values (Figure 7). Comparatively the aged sample demonstrated lower average axial stiffness values (by 16-25\%) for the harmonic loading intervals contained within load set LS1. At first this trend appears to contradict the results of dynamic loading tests reported by Bitting [6], who noted that the axial stiffness of aged $1 / 2$ " diameter rope samples increased significantly after deployment at sea for five years. However, it is notable that for mean loads of a similar magnitude to those used in this study (i.e. less than $14 \% \mathrm{MBL}$ ) lower stiffness values were reported for aged 8-strand plaited ropes in [6]. In the current study the trend of increasing axial stiffness with the application of higher mean load levels is noted for both new and aged samples (Figure 7a), as observed in other studies $[16,24,44,47]$. A single degree-of-freedom line fitted to mean load and axial stiffness values (both normalised by the rope MBL) can be used to quantify the dynamic stiffness of a sample [7]. Defined in terms of trend line gradient $(m)$ and $y$-intercept $(c)$ values: $K r D=m\left(\frac{F_{\text {mean }}}{M B L}\right) * 100+c$, dynamic stiffness values are listed in Table 2 for both samples NS2 and AS1. For reference, values reported by François et al. in [24] are also listed for a parallel strand polyester rope (800 Tonne MBL) subjected to 100 cycles including higher mean loads (6-50\% MBL) and several amplitude ranges. It can be seen that gradient values for both new and aged samples are similar over the range of mean loads used in this study with a lower $y$-intercept related to the reduction in stiffness with aging. Both new and aged ropes samples exhibit a gradual increase of damping with mean load, and a notable decrease in damping with increasing load rate (Figure 7b). Average axial stiffness and damping values reflect the steady-state performance of the samples. However as reported in the previous study [47], both of these properties are time-dependent (Figure 8) and this effect will be particularly important for ropes subjected to the unsteady loading conditions of small offshore equipment (e.g. MRE devices). 


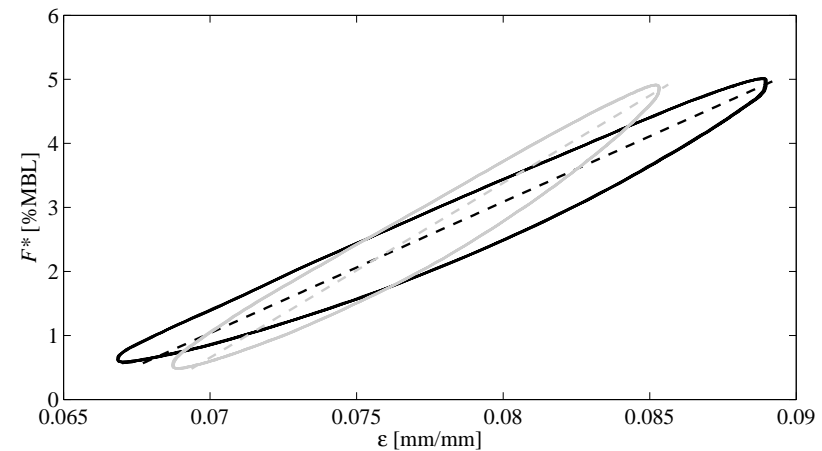

Figure 6: Example of new rope sample NS2 (grey line) and aged rope sample AS1 (black line) hysteresis loops for the last five cycles of harmonic loading (100 s oscillation period, load level $\mathrm{A}$ in load set LS1). Fitted single degree-of-freedom lines (both: $R^{2}=0.95$ ) for the last cycle of each interval are also shown as dashed lines. Measured loads are expressed as a percentage of the rope $\mathrm{MBL}(F *=F / M B L)$.

\subsubsection{Yarn assembly samples}

The quantified differences between the performance of the aged and new rope samples are indicative of conditioning occurring during use. To determine if the observed variations in performance are attributable to material or constructional changes, tests were conducted on yarn assembly samples at IFREMER using the experimental setup introduced in Section 2.3. The difference in stiffness noted for the new and aged rope samples was also observed when the yarn assembly samples were loaded to failure at a constant load rate (Figure 9). The new and aged load-strain curves diverge with increasing applied load, with failure of the aged yarn assemblies occurring at a lower average strain $(15 \%)$ and average break load (BL) level (20\%) than for the new yarn assemblies (Table 3). There is notably more variation in the breaking loads and strains of the aged samples, compared to the new samples. Whilst it is possible that the three aged samples achieved a different material state in-service, the performance variations are also partly due to the less uniform structure of the aged yarn assemblies (i.e. compaction was observed in particular locations) compared to the new samples. Although care was taken to avoid damage to the aged samples as they were extracted from the SWMTF mooring rope and efforts were made to ensure that the samples had the same twist angle, it is likely that constructional rearrangement occurred at different load levels during the load-to-failure test. Repetition of the tests on yarn assemblies from one of the outer subropes achieved similar breaking load and strain values (Table 3 ).

An additional six new and aged yarn assemblies were subjected to triangular waveform loading with loading regimes scaled from load levels A-E of LS1. Scatter is observed in the average axial stiffness and damping values presented 


\begin{tabular}{|c|c|c|c|}
\cline { 3 - 4 } \multicolumn{1}{c|}{} & \multirow{2}{*}{ New } & \multicolumn{2}{c|}{ Aged } \\
\cline { 3 - 4 } \multicolumn{1}{c|}{} & & Central & Outer \\
\hline Load [N] & $3305-3331$ & $2620-2743$ & $2529-2825$ \\
\hline$\varepsilon[\mathbf{m m} / \mathbf{m m}]$ & $0.203-0.204$ & $0.168-0.177$ & $0.168-0.176$ \\
\hline
\end{tabular}

Table 3: Maximum loads and strains achieved by the three new and three aged yarn assemblies before failure. Distinction is made which location the aged samples originated from (central or outer subropes).

in Figure 10 which may be related to the performance variations observed in the load-to-failure tests at similar loads. Maximum strains of between 4.5 and $6.5 \%$ were measured during the scaled harmonic tests, which is considerably lower than the maximum strains measured during harmonic rope testing (up to $13.8 \%$ for load level E). Although direct comparison between the rope and yarn tests is not possible, this difference implies that rope elongation is due to both the properties of the material and the interaction of yarn assemblies within the rope structure.

\subsection{Harmonic/irregular loading performance}

Calculated strain values for the new and aged rope samples subjected to load set LS3 are presented in Figure 11 based on alignment of both force timeseries by the minimum force measurement of the first load/unload cycle (at $t=63.4 \mathrm{~s}$ ). Relevant measurements are contained within datasets 'Inline Supplementary NS2_LS3_Dry.txt' and 'Inline Supplementary AS1_LS3_Dry.txt'. Higher strain values and strain ranges for the aged sample are clearly apparent. As with the tests conducted using load set LS1, greater strain ranges are conducive with a reduction in axial stiffness, with the difference between the aged and new samples equal to 4.0-8.1\% for the harmonic intervals of LS3 (Table 4). The reduction of axial stiffness is of a lower magnitude than for the LS1 results presented in Figure 7. The average axial stiffness values calculated for this load set suggest a departure at low mean loads from the linear trend characterised by the dynamic stiffness values listed in Table 2. Contrary to the damping values calculated for the LS1 set, there is a marginal decrease in damping for the aged rope sample. As reported in the previous study [47], large stiffness values were calculated for the irregular calm interval (load level R; Figure 12), higher than those associated with the irregular mild-storm interval (load level S) and these results are due to small amplitude load cycling. The performance of the two samples during the mild-storm interval is of particular interest. Due to the diversity of load amplitudes, mean loads and load rates contained within the mild-storm interval, it is not possible to identify clear axial stiffness and damping trends beyond broad generalisations (i.e. for the majority of cycles within the mild-storm time-series the variance of calculated stiffness values is smaller for the aged sample, Figure 12). In agreement with the previous study, these results are indicative of the time-dependency of rope axial stiffness and damping in transient loading conditions. 


\begin{tabular}{|c|c|c|c|c|c|c|}
\hline & \multicolumn{4}{|c|}{ Sample } \\
\hline & & & \multicolumn{2}{|r|}{ New } & \multicolumn{2}{|r|}{ Aged } \\
\hline & & & $E A *$ & $B[\mathrm{kNs} / \mathrm{m}]$ & $E A *$ & $B[\mathrm{kNs} / \mathrm{m}]$ \\
\hline \multirow{6}{*}{ 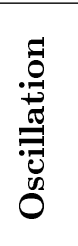 } & \multirow{6}{*}{ 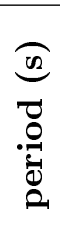 } & 100 & 2.1 & 203.9 & 1.9 & 189.1 \\
\hline & & 50 & 2.0 & 106.0 & 2.0 & 104.1 \\
\hline & & 25 & 2.2 & 52.7 & 2.1 & 46.8 \\
\hline & & 9 & 2.4 & 19.4 & 2.3 & 17.5 \\
\hline & & 6 & 2.5 & 12.7 & 2.3 & 11.8 \\
\hline & & 3 & 2.6 & 6.6 & 2.5 & 6.4 \\
\hline
\end{tabular}

Table 4: Average axial stiffness values (normalised by the rope MBL: $E A *=E A / M B L$ ) and damping for the new and aged rope samples subjected to low load harmonic loading (load level Q)

\section{Performance of dry and saturated samples}

When drawn nylon fibre is immersed in water for long periods hydrolysis can result in molecular chain breakage and there is a subsequent reliance on the crystallite regions of the polymer for structural integrity. In addition, swelling occurs by approximately $2 \%$ in the transverse direction and up to $7 \%$ in the longitudinal direction [41]. The subsequent reduction in strength and stiffness (typically $15 \%$ at $65 \%$ relative humidity; [35]) and reduction in fatigue performance [5] are well documented but not in the context of loads relevant to MRE mooring systems. To address this knowledge gap, the new and aged rope samples NS2 and AS1 were subjected once again to LS3 after each sample had been soaked for 31 and 32 days respectively in tap water. Relevant measurements are contained within datasets 'Inline Supplementary NS2 LS3_Wet.txt' and 'Inline Supplementary AS1_LS3_Wet.txt'. The effect of saturation on the new sample was significant in terms of strain (Figure 13), to the extent that during the last five cycles of the $100 \mathrm{~s}$ harmonic interval the average strain and strain amplitude increased by $61.1 \%$ and $53.2 \%$ respectively. The aged sample exhibited smaller increases of average strain and strain amplitude for the same harmonic interval ( $31.2 \%$ and $46.2 \%$ respectively). Increased compliance of each sample is reflected in an appreciable reduction in stiffness (Table 5 and Figure 14) that is considerably greater than what has been reported in the literature. François et al. in [24] reported a reduction in stiffness of approximately one third after soaking several double braid nylon rope samples for 11 days. In the current study, reductions in damping are also noted after sample saturation and the large differences cannot be explained by a change in material state due to hydrolysis alone. In [24] it is suggested that the increased compliance of the saturated samples is probably also due to the lubrication of contacting rope elements within the structure. One further consideration is that permanent damage may have occurred during dry testing of the new and aged samples, meaning that the condition of each sample at the start of the dry and wet tests would be different. However, whilst the measured strain values at the end of the test indicate an offset (Figure 13), strain recovery may have taken place during storage and soaking. The compliance of samples after saturation was also demonstrated by the behaviour of saturated samples (NS5 and NS6) subjected to the bedding-in cycle of load set LS4 (Figure 15). Comparatively these samples achieved strains up to $18.1 \%$ higher than the dry sample (NS4) 


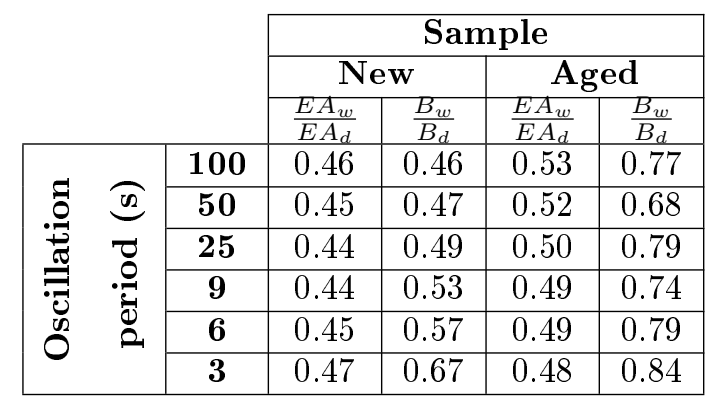

Table 5: Ratio of wet (subscript ' $w$ ') to dry (subscript 'd') average axial stiffness and damping for the new and aged rope samples subjected to low load harmonic loading (load level Q)

during the bedding-in cycle. Although the two saturated samples demonstrated differences in strain and load at failure, this is likely to be due to performance variability instead of the influence of salinity. Relative to the minimum break load specified by the manufacturer the saturated samples failed at $100.5 \% \mathrm{MBL}$ and 96.1\% MBL respectively for NS5 and NS6. Both failures occurred along the free length of the samples and some limited damage was sustained to the splices close to the rope eyes (Figure 16).

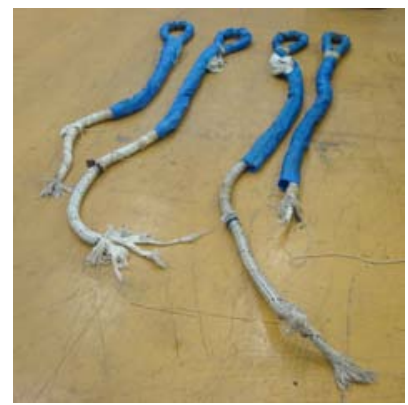

Figure 16: Failed rope samples (left) NS5 and (right) NS6 after load-to-failure tests LS4

\section{Damage assessment}

The test results reported in this study indicate a consistent difference between the performance of the new and aged rope and yarn assembly samples. The performance of the aged samples is symptomatic of mild damage occurring during the first SWMTF deployment. Given the loading conditions experienced by the SWMTF mooring lines (Figure 17a) and based on visual inspections of 
the rope, the damage can be attributed to two primary mechanisms: i) abrasion wear between the outer yarns and jacket due to sediment and mussel infiltration (Figure 17b) and ii) fibre-on-fibre wear occurring during tension-tension fatigue cycling (Figure 17c). Rapid cycling over large load ranges due to snatch loading may also have contributed to the observed differences in performance. Whilst the SWMTF mooring lines were not overloaded during the first deployment (most loads were under 8\% MBL [47]), snatch loads of up $11.2 \% \mathrm{MBL}$ were measured. With a typical mooring line pretension load of less than $1 \%$ MBL [47], creep is unlikely to have contributed to material degradation during the SWMTF deployment. In contrast to other recovered offshore ropes (e.g. [23]), the level of wear observed in scanning electron microscope (SEM) images, produced using FEI Quanta 200 equipment, suggest gradual abrasion with no peeling of the fibre surfaces or localised melting visible at macroscopic scale (Figure 17c). No cuts or broken fibres were observed from the SEM images produced for this study (which are effectively surveys at several points only) and the non-load-bearing rope jacket only experienced minor abrasion. However, it is likely that the particles of grit or the juvenile mussels found within the rope structure (Figure 17b) will have contributed to fibre damage by acting as an abrasive medium and hence accelerated fibre-on-fibre wear, as has been noted in other studies (e.g. [20,4]). Certain regions of the outer subropes were notably discoloured, suggesting sediment transport through the woven outer jacket. To quantify the residual fatigue durability of aged yarns extracted from the SWMTF rope, yarn-on-yarn abrasion tests were conducted on new and aged yarns tested in natural sea water. In Figure 18 it can be seen that most of the aged samples and several new samples failed after a lower number of cycles than the minimum values specified in the Cordage Institute 2009N guidelines [13]. The high number of cycles to failure exhibited by the new samples at the lowest mean load is an indication of abrasion resistance and retention of the marine finish coating applied during manufacture. The durability of a wet nylon subropes to tension-tension fatigue cycling was demonstrated in [43], which reported no loss of residual strength after one particular subrope was subjected to 51,000 load cycles. In the current study the number of cycles to failure achieved by the aged yarn samples are significantly lower than the new samples, particularly at high load levels and this is probably due to the reduced effectiveness of the marine finish due to abrasion wear. 


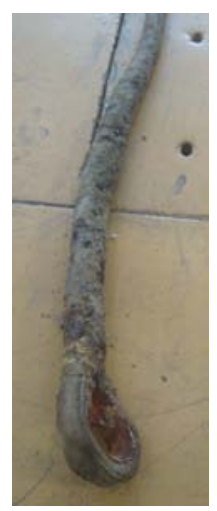

(a)

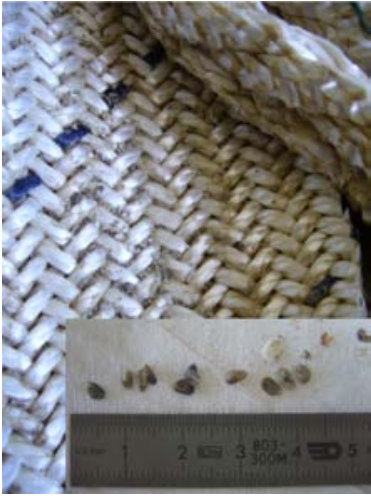

(b)

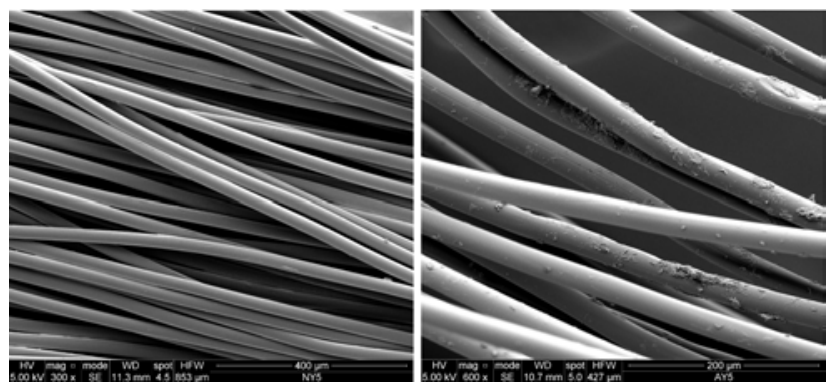

(c)

Figure 17: a) Recovered SWMTF aged rope after removal of the bio-fouling. b) Grit and juvenile mussel shells observed within the aged rope structure and c) SEM images of (left) new and (right) aged fibres at two magnification scales. Biological detritus and wear recesses are apparent on some of the aged fibres.

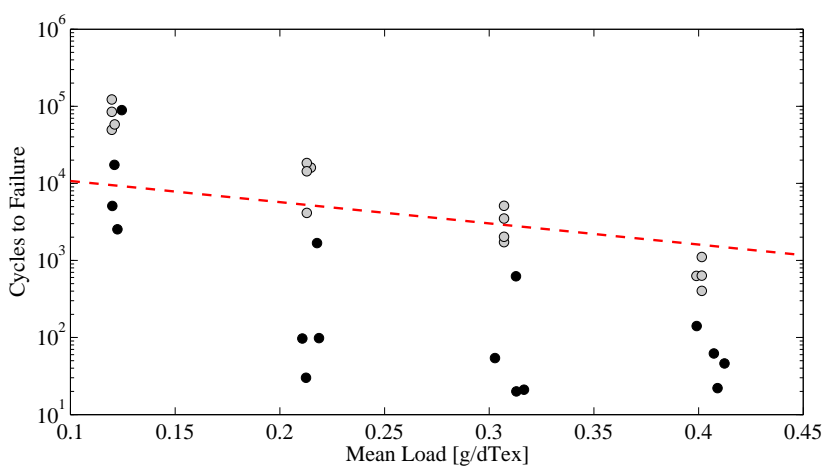

Figure 18: Yarn-on-yarn abrasion tests of new and aged yarns (grey and black lines respectively). Minimum cycles to failure as defined in [21] are shown as a dashed red line. (For interpretation of the references to colour in this figure legend, the reader is referred to the online version of this paper.) 
As part of a scheduled maintenance, inspection of mooring ropes including the condition of splices and eyes is carried out to assess the level of damage sustained in-service $[17,18,36]$. Damage to internal rope elements would not be apparent from visual inspection of the rope exterior using remotely operated vehicle equipment or by recovery of the rope. If damage is suspected then internal inspection is necessary to ensure that the residual strength of the rope is sufficient for the application. The use of recoverable inserts for deep water mooring applications [38] has questionable relevance for the relatively shallow water depths proposed for MRE devices. In the absence of a means to continuously monitor the structural health of mooring ropes, it would be prudent to carry out periodic visual inspections and continuously monitor mooring tensions. Ropes that have been identified as possibly sustaining damage should then be recovered in their entirety and subjected to laboratory testing to determine residual strength.

\section{Conclusions}

With a proven track record of use in the offshore industry, synthetic ropes have the potential to be an enabling technology with a key role to play in the economical development of large scale commercial MRE deployments. Despite extensive experience acquired from offshore platform and vessel station-keeping, only a few R\&D programmes have focused on their use for MRE mooring systems and hence fundamental uncertainties exist regarding the performance and long-term durability of these materials in this new application. It has been the intention of this two-part study (first part: [47]) to give previously unseen insight into the response behaviour of a commercially available nylon mooring rope construction when subjected to highly dynamic loading conditions. The results have demonstrated that the applied load history and operating conditions both have a significant influence on the instantaneous properties of the rope. Three response characteristics which are important for the design of MRE mooring systems have been quantified; strain, axial stiffness and damping, with tests conducted on new and aged samples in dry and saturated states. The study has demonstrated that the progressive application of harmonic load cycles to new rope samples will lead to a short-term increase of axial stiffness and reduction of damping. The results indicate that these properties are likely to reach a steady-state with continued harmonic loading. However, it is evident from the time-dependent responses measured in this study for rope samples subjected to irregular loading regimes that the standard approach of applying hundreds or thousands of load cycles to synthetic rope assemblies or yarns is not representative of the load conditions typically experienced by buoy-like MRE devices. In addition to load history, the influence of aging on rope properties has been investigated utilising rope and yarn samples taken from a mooring rope used during the first deployment of the SWMTF. When subjecting new and aged rope samples to the same loading conditions, notably larger average strains and strain amplitudes were demonstrated by the aged sample, as well as a reduction in axial stiffness and an increase in damping. Similar behaviour was exhibited by new and aged yarn assemblies. The increase in compliance and reduction of strength of the aged samples is symptomatic of abrasion wear caused primarily by tension-tension fatigue cycling during the 18 month deployment. Damage 
sustained through this mechanism will have been accelerated by the ingress of particles including debris and marine growth (i.e. mussels). This conclusion is based on tension-tension testing based on measured SWMTF mooring tensions, scanning electron microscope analysis of extracted fibres as well as load-to-failure and cycle-to-failure tests. These findings clearly demonstrate the importance of preventing particles from penetrating through to the load bearing elements of the rope. The additional cost of selecting a rope construction with a particle filter layer will be offset by the increased functional lifetime of the rope, and be negligible compared to the costs associated with the in situ replacement of mooring lines, particularly for 10s or 100s of MRE devices in an array. The results reported in this study have also highlighted the transient nature of rope properties with load history and damage. It is therefore crucial that the sensitivity of device response to such variations is analysed at the mooring system design stage. Significant permanent extension and increased compliance of the mooring rope(s) will reduce the overall stiffness and hence the station-keeping abilities of the mooring system. If the lines are not subsequently re-tensioned then large device motions may occur which could result in damage to adjacent devices in the case of MRE arrays. Both laboratory assessments and in situ condition monitoring will continue to provide a greater insight into the performance and structural health of subsea mooring components.

\section{Acknowledgment}

The authors would like to acknowledge the support of the MERiFIC project partners. The project is funded by the European Regional Development Fund through the Interreg IV-A programme. Through the Peninsula Research Institute for Marine Renewable Energy (PRIMaRE) consortium, the DMaC test facility and SWMTF were funded from the ERDF Convergence programme and South West Regional Development Agency.

[1] American Bureau of Shipping, 2011. Guidance Notes on the Application of Fiber Rope for Offshore Mooring.

[2] American Petroleum Institute, 2012. Recommended Practice for Design, Manufacture, Installation and Maintenance of Synthetic Fiber Ropes for Offshore Mooring. Draft Second Edition.

[3] ASTM International, 2007. Standard test method for wet and dry yarn on yarn abrasion resistance, ASTM D-6611.

[4] Ayres, R, 2001. Characterizing polyester rope mooring installation damage. Technical Report to the U.S. Minerals Management Service and the Offshore Technology Research Center.

[5] Backer, S., McGarry, F.J., Williams, J.H., 1981. Deterioration of synthetic fiber rope during service.

[6] Bitting, K.R., 1980. The dynamic behaviour of nylon and polyester line. DTIC report CG-D-39-80. 
[7] Bureau Veritas, 2007. Certification of Fibre Ropes for Deepwater Offshore Services. Guidance note: NI 432 DTO R01E. Bureau Veritas, Paris, France.

[8] Carbon Trust and Black \& Veatch, 2011. Accelerating marine energy. the potential for cost reduction - insights from the Carbon Trust Marine Energy Accelerator.

[9] Chailleux, E., Davies, P., 2003. Modelling the Non-Linear Viscoelastic and Viscoplastic Behaviour of Aramid Fibre Yarns. Mechanics of TimeDependent Materials 7, 291-303.

[10] Cordage Institute, 2001a. Determination of marine finish on synthetic fiber yarns. Technical Report TR2009.

[11] Cordage Institute, 2001b. International guideline fiber rope inspection and retirement criteria guidelines to enhance durability and the safer use of rope. CI 2001-04.

[12] Cordage Institute, 2009. Test method for yarn-on-yarn abrasion, wet and dry. Test Method CI 1503-09.

[13] Cordage Institute, 2013. Performance requirements for marine grade nylon yarn for fiber rope. CI Guideline 2009N.

[14] da Costas Mattos, H.S., Chimisso, F.E.G., 2011. Modelling creep tests in HMPE fibres used in ultra-deep-sea mooring ropes. International Journal of Solids and Structures 48, 144-152.

[15] Davies, P., Chailleux, E., Bunsell, A., Grosjean, F., François, M., 2003. Prediction of the long term behavior of synthetic mooring lines, in: Proceedings of the Offshore Technology Conference (OTC 15379), Houston, USA.

[16] Davies, P., Reaud, Y., Dussud, L., Woerther, P., 2011. Mechanical behaviour of HMPE and aramid fibre ropes for deep sea handling operations. Ocean Engineering 38, 2208-2214.

[17] Det Norske Veritas, 2005. Damage assessment of fibre ropes for offshore mooring: DNV-RP-E304.

[18] Det Norske Veritas, 2010. Offshore standard - offshore mooring fibre ropes. DNV-OS-E303.

[19] Det Norske Veritas, 2013. Offshore standard - position mooring. DNV-OSE301.

[20] Devlin, P., Flory, J., Homer, S., 1999. Deepstar taut leg mooring polyester test program, in: Proceedings of OCEANS '99 MTS/IEEE, Seattle, USA.

[21] Flory, J.F., 2013. Cordage institute guidelines for marine grade nylon and polyester rope-making yarns, in: Proceedings of the OCEANS 2013 conference, San Diego, USA. 
[22] Flory, J.F., Banfield, S.J., Petruska, D.J., 2004. Defining, Measuring, and Calculating the Properties of Fiber Rope Deepwater Mooring Lines, in: Proceedings of the Offshore Technology Conference (OTC 16151), Houston, USA.

[23] Flory, J.F., Leech, C.M., Banfield, S.P., Petruska, D.J., 2005. Computer Model to Predict Long-Term Performance of Fiber Rope Mooring Lines, in: Proceedings of the 2005 Offshore Technology Conference (OTC 17592), Houston, USA.

[24] François, M., Davies, P., Grosjean, F., Legerstee, F., 2010. Modelling of fibre rope load-elongation properties - Polyester and other fibres, in: Proceedings of the 2010 Offshore Technology Conference (OTC 20846), Houston, USA.

[25] Ghoreishi, S.R., Cartraud, P., Davies, P., T, M., 2007. Analytical modeling of synthetic fiber ropes subjected to axial loads. Part I: A new continuum model for multilayered fibrous structures. International Journal of Solids and Structures 44, 2924-2942.

[26] IEC, 2013. Marine energy - Wave, tidal and other water current converters - Part 10: The assessment of mooring system for marine energy converters. IEC-TS 62600-10 Ed.1.0 (In-Progress).

[27] International Standards Organisation, 2007. Fibre ropes for offshore station keeping - Polyester. ISO 18692.

[28] Johanning, L., Smith, G.H., Wolfram, J., 2007. Measurements of static and dynamic mooring line damping and their importance for floating WEC devices. Ocean Engineering 34, 1918-1934.

[29] Johanning, L., Thies, P.R., Parish, D., Smith, G.H., 2011. Offshore reliability approach for floating renewable energy devices, in: Proceedings of the 30th International Conference on Ocean, Offshore and Artic Engineering, Rotterdam, Netherlands.

[30] Kenny, M.C., Mandell, J.F., McGarry, F.J., 1985. The effects of sea water and concentrated salt solutions on fatigue of nylon 6,6 fibres. Journal of Materials Science 20, 2060-2070.

[31] Leech, C.M., Banfield, S.J., Overington, M.S., Lemoel, M., 2003. The prediction of cyclic load behaviour and modulus modulation for polyester and other large synthetic fiber ropes, in: Proceedings of the OCEANS 2003 conference, pp. 1348-1352.

[32] Low Carbon Innovation Coordination Group, 2012. Technology Innovation Needs Assessment (TINA): Marine Energy Summary Report.

[33] Ma, K.t., Duggal, A., Smedley, P., L'Hostis, D., Shu, H., 2013. A Historical Review on Integrity Issues of Permanent Mooring Systems, in: Proceedings of the Offshore Technology Conference (OTC 24025), Houston, USA.

[34] Mason, AJ, 1999. An Experimental Investigation of Damaged Arresting Gear Tapes for the Langley Aircraft Landing Dynamics Facility. NASA/TM-1999-209839. 
[35] McKenna, H A and Hearle, J W S and O'Hear, N, 2004. Handbook of Fibre Rope Technology. Woodhead Publishing Limited, Cambridge, UK.

[36] Noble Denton Europe Limited , 2006. Floating production system JIP FPS mooring integrity. Research Report 444 prepared for the Health and Safety Executive.

[37] Oil Companies International Marine Forum, 2000. Guidelines for the purchasing and testing of SPM hawsers.

[38] Otten, J.D., Leite, S., 2013. Thunder Hawk Mooring Rope Particle Ingress, Break, and Fatigue Testing, in: Proceedings of the 2013 Offshore Technology Conference (OTC 24080), Houston, USA.

[39] Overington, M.S., Leech, C.M., 1997. Modelling Heat Buildup In Large Polyester Ropes. International Journal of Offshore and Polar Engineering 7 .

[40] Paredes, G.M., Bergdahl, L., Palm, J., Eskilsson, C., Pinto, F.T., 2013. Station keeping design for floating wave energy devices compared to offshore oil and gas platforms, in: Proceedings of the 10th European Wave and Tidal Energy Conference, Aalborg, Denmark.

[41] Richards, A.F., 2005. Synthetic fibres: nylon, polyester, acrylic, polyolefin. Woodhead Publishing Limited, Cambridge, UK.

[42] Ridge, I.M.L., Banfield, S.J., Mackay, J., 2010. Nylon Fibre Rope Moorings for Wave Energy Converters, in: Proceedings of the OCEANS 2010 conference, Seattle, USA.

[43] Tension Technology International Ltd, 2013. Nylon fibre ropes for WEC Moorings. WP1 Milestone 6 - Final Report. Carbon Trust Reference number: 0912-050.

[44] Thies, P.R., Johanning, L., Gordelier, T., Vickers, A., Weller, S., 2013. Physical component testing to simulate dynamic marine load conditions, in: Proceedings of the 32nd International Conference on Ocean, Offshore and Arctic Engineering, Nantes, France.

[45] Vlasblom, M., Boesten, J., Leite, S., Davies, P., 2012. Development of HMPE Fiber for permanent deepwater offshore mooring, in: Proceedings of the Offshore Technology Conference (OTC 23333), Houston, USA.

[46] Weller, S., Davies, P., Thies, P.R., Harnois, V., Johanning, L., 2012. Durability of synthetic mooring lines for ocean energy devices, in: Proceedings of the 4th International Conference on Ocean Energy, Dublin, Ireland.

[47] Weller, S., Davies, P., Vickers, A., Johanning, L., 2014. Synthetic Rope Responses in the Context of Load History: Operational Performance. Ocean Engineering 83, 111-124. 

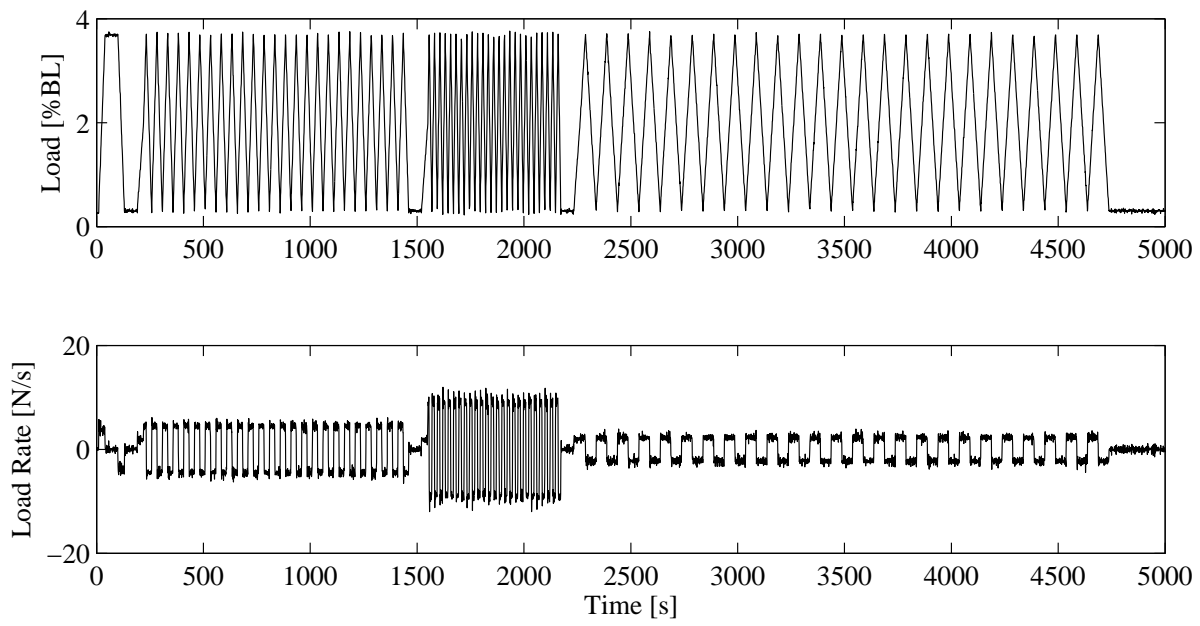

Figure 3: Measured loads (expressed as a percentage of the new yarn assembly average BL) and load rate time-series for the dynamic load test based on scaled load level A of load set LS1

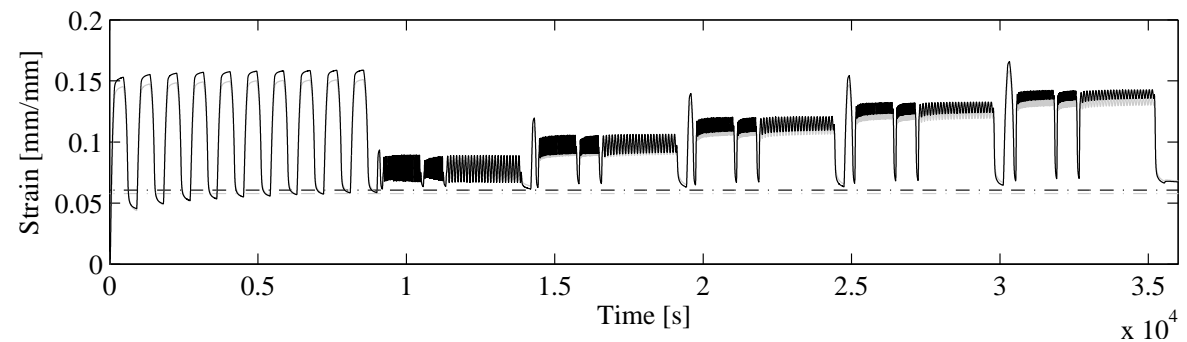

Figure 5: Calculated time-varying strain values for new rope sample NS2 (grey line) and aged sample AS1 (black line) during the first $9.9 \mathrm{~h}$ of testing. The strain of the two samples after $10.8 \mathrm{~h}$ of steady loading are shown as dash-dot lines 

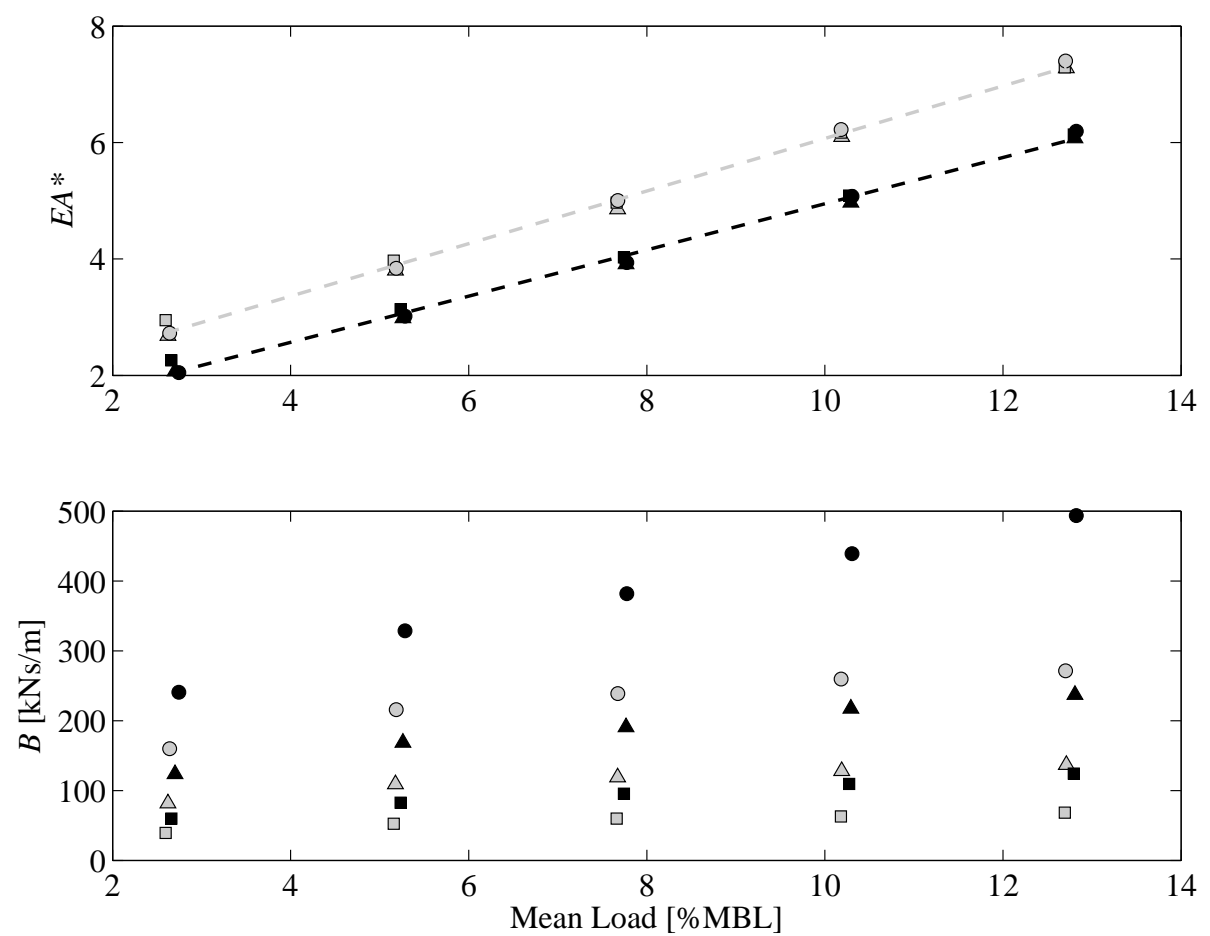

(a)
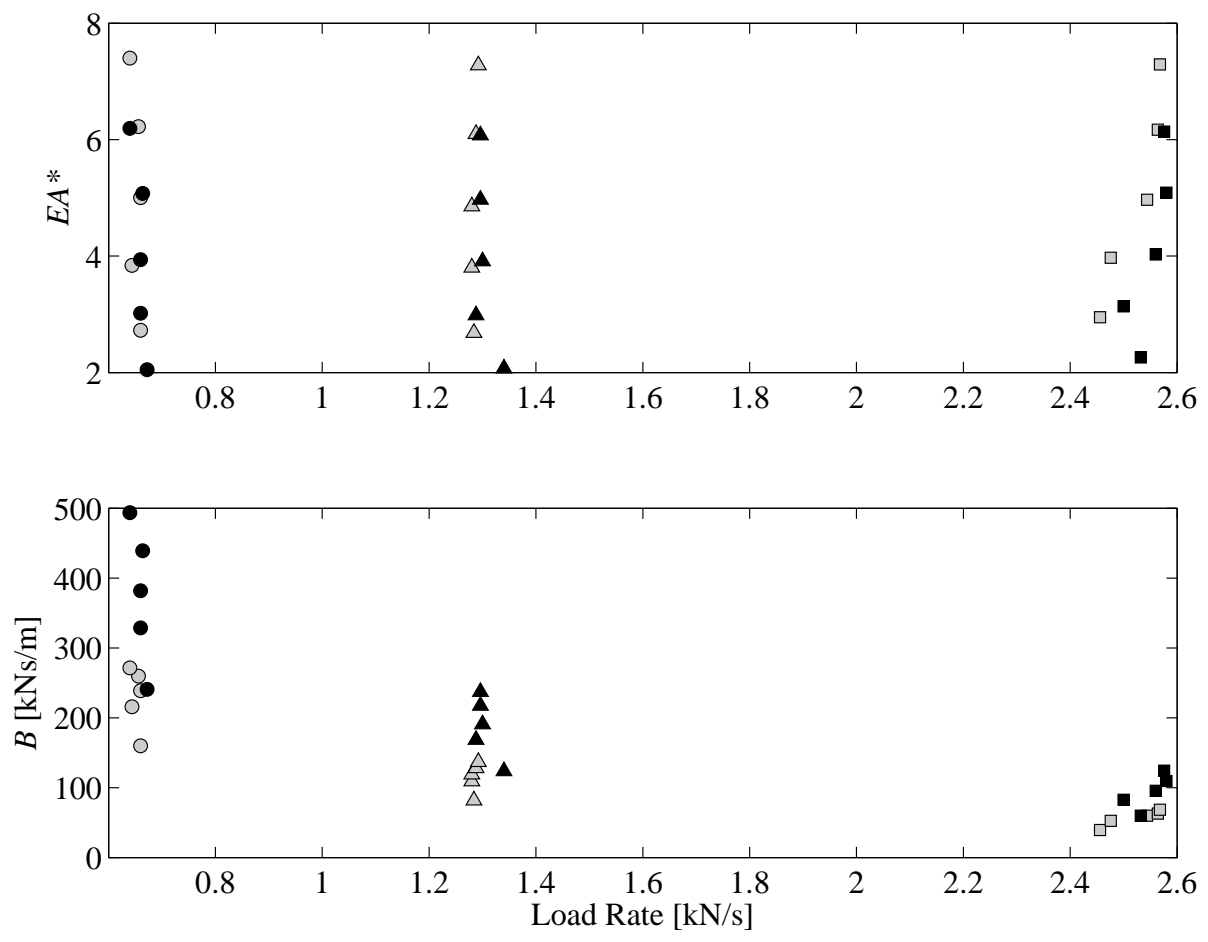

(b)

Figure 7: Variation of average $(t o p)$ axial stiffness (normalised by the rope MBL; $E A *=$ $E A / M B L)$ and (bottom) damping values with a) mean load (expressed as a percentage of the rope MBL) and b) maximum absolute load rate for load set LS1. Results are shown for new and aged rope samples (grey and black markers respectively) and for oscillation periods, 100 $\mathrm{s}(\bigcirc), 50 \mathrm{~s}(\triangle)$ and $25 \mathrm{~s}(\square)$. 

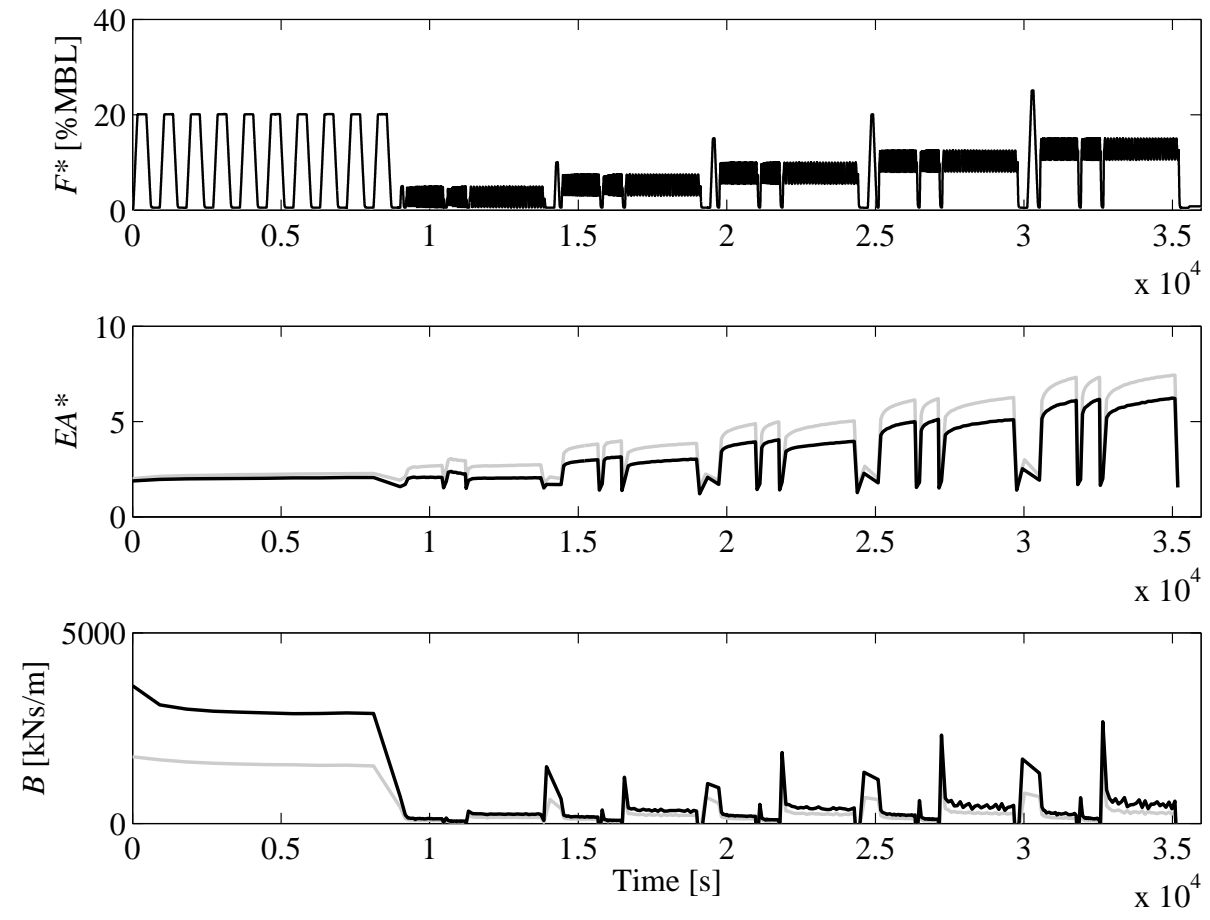

Figure 8: Cycle-by-cycle calculated axial stiffness $(E A)$ and damping $(B)$ for the new (grey line), and aged (black line) rope samples subjected to bedding-in and load levels A-E (from LS1). Negative damping values which correspond to extension-load loops which include sample recovery between harmonic intervals are not shown. For reference the load time-series applied to each sample are also shown as a percentage of the rope MBL $(F *=F / M B L)$. The axial stiffness values are normalised by the rope $\mathrm{MBL}(E A *=E A / M B L)$.

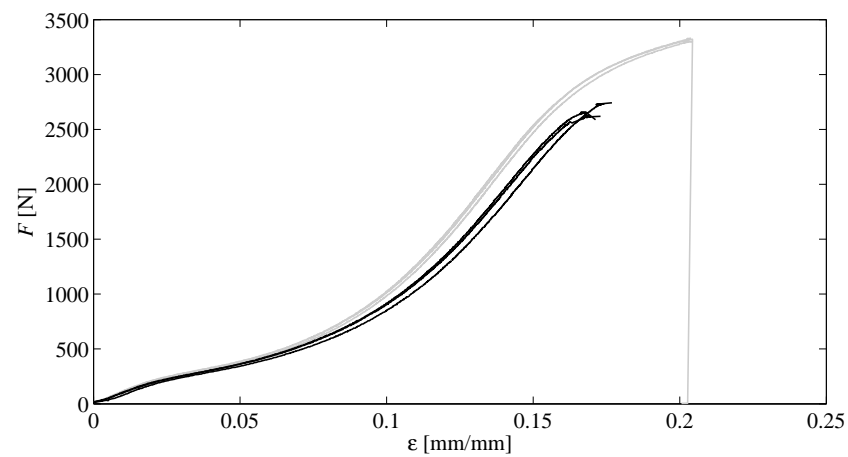

Figure 9: Load-strain failure curves for the new (grey line), and aged (black line) yarn assembly samples subjected to a constant load rate $(10.1 \mathrm{~N} / \mathrm{s})$. The aged samples originated from the central subrope of the SWMTF rope. 

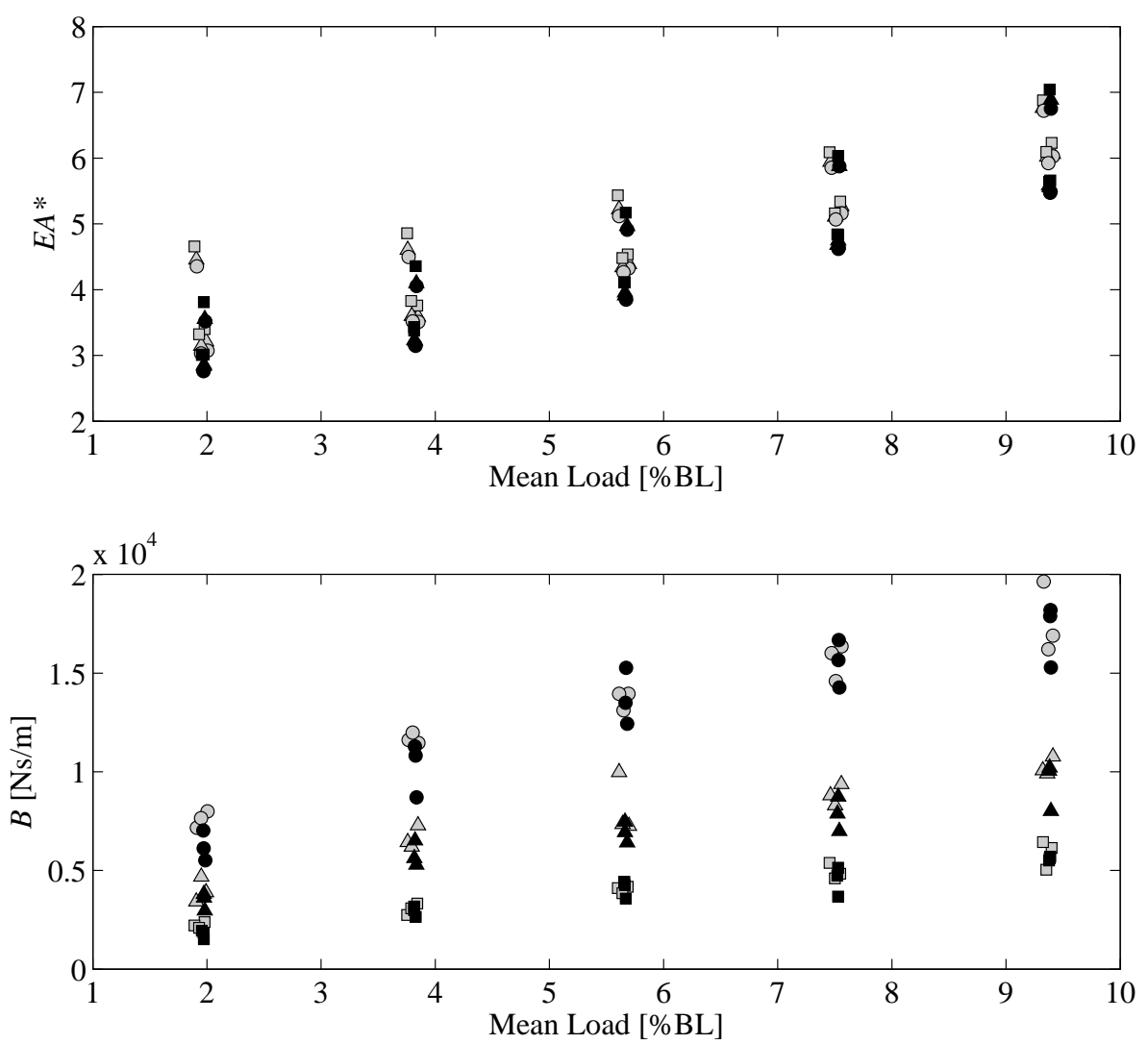

Figure 10: Average (top) axial stiffness (normalised by the average new yarn assembly BL; $E A *=E A / B L)$ and (bottom) damping values with mean load (expressed as a percentage of the average new yarn assembly BL) for new and aged yarn assemblies (grey and black markers respectively) subjected to triangular waveform loading scaled from load levels A-E of LS1. Results are shown for oscillation periods, $100 \mathrm{~s}(\bigcirc), 50 \mathrm{~s}(\triangle)$ and $25 \mathrm{~s}(\square)$.

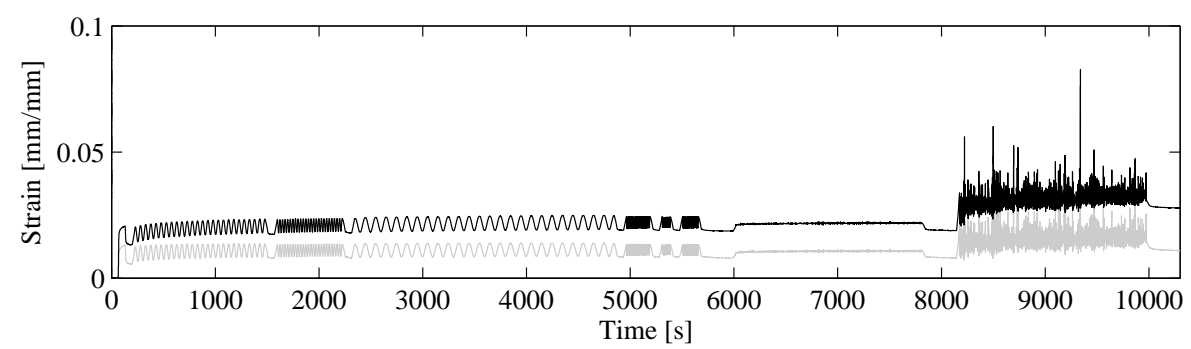

Figure 11: Calculated time-varying strain values for new and aged rope samples (grey and black lines respectively) subjected to mixed harmonic and irregular load time-series. 

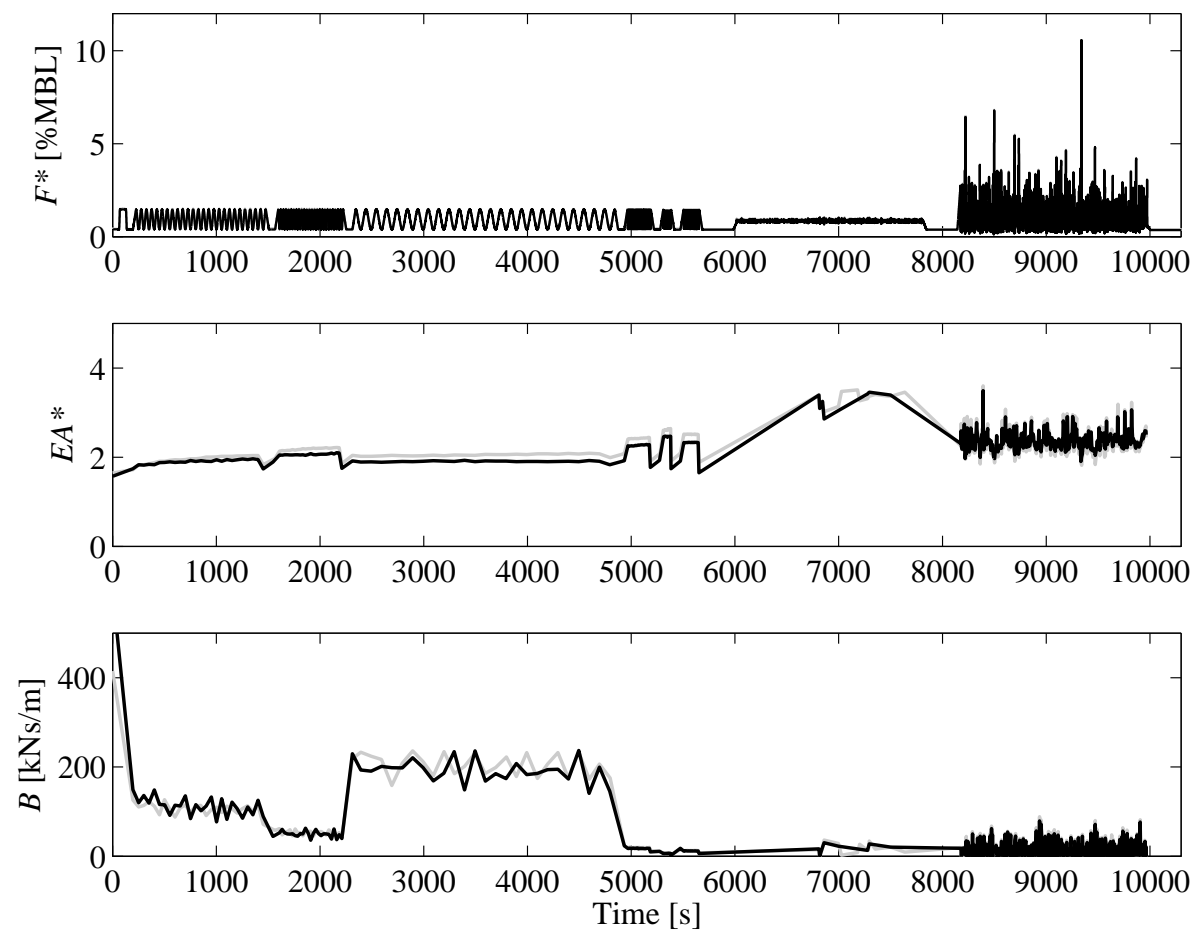

Figure 12: As Figure 8 for load levels Q-S (from LS3). Cycles with load ranges less than 1.0 $\mathrm{kN}$ are not displayed. 


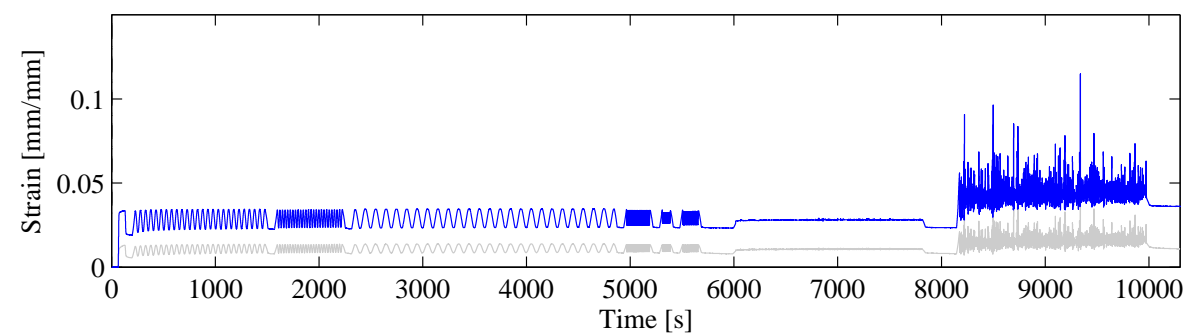

(a)

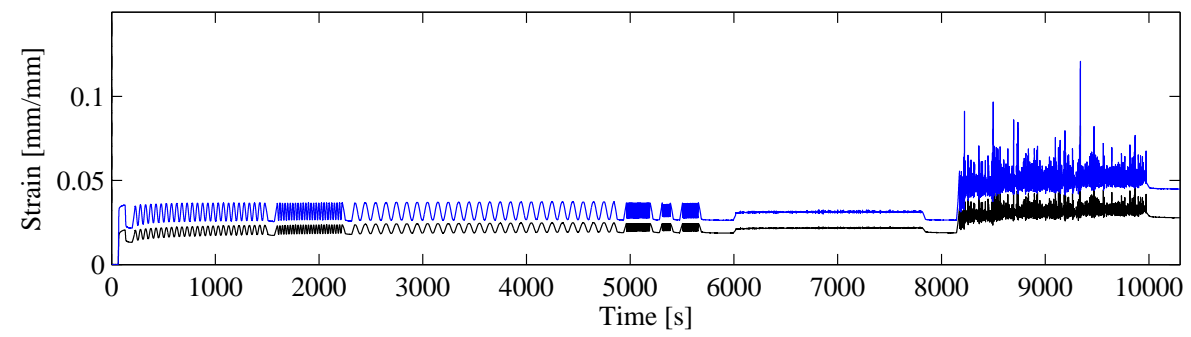

(b)

Figure 13: Calculated time-varying strain values for a) new and b) aged rope samples (grey and black lines respectively) subjected to mixed harmonic and irregular load time-series. Strain values for the same samples after saturation are shown as blue lines. The time-series have been aligned by the minimum force measurement of the first load/unload cycle (at $t=61.5 \mathrm{~s}$ ). (For interpretation of the references to colour in this figure legend, the reader is referred to the online version of this paper.) 

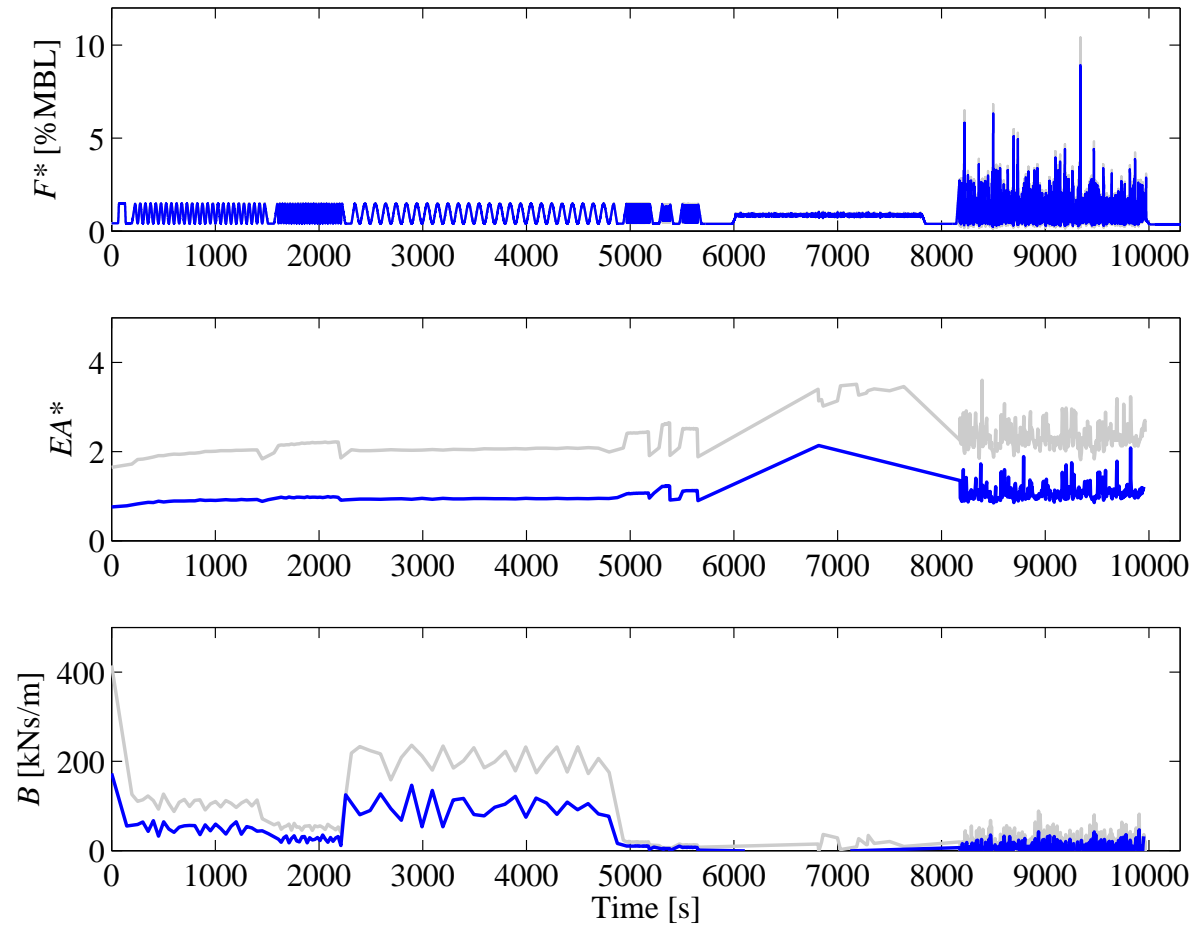

(a)
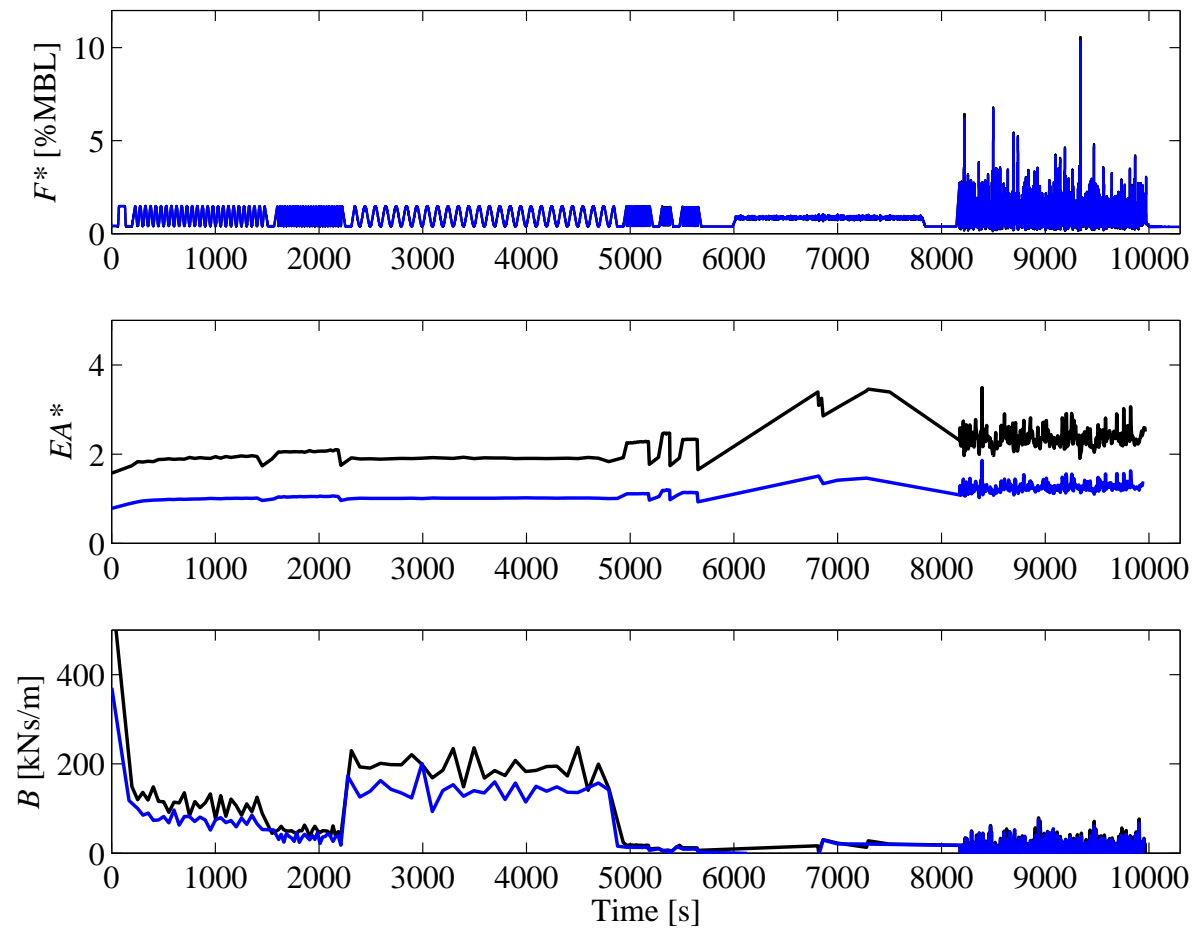

(b) 


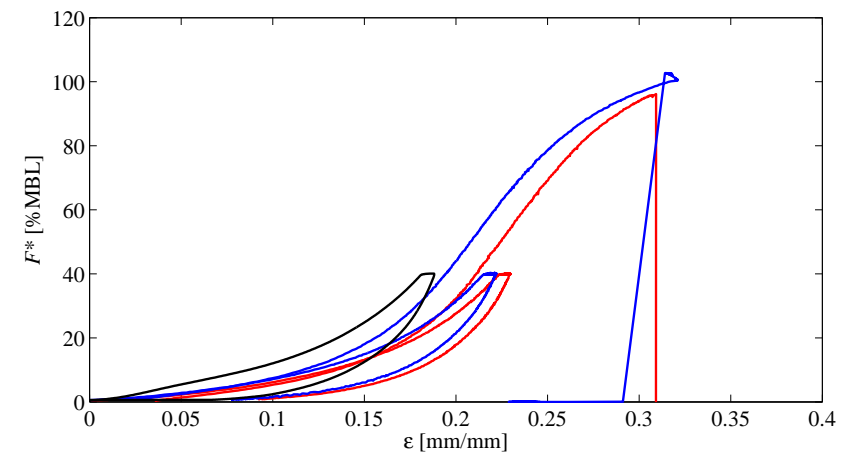

Figure 15: Load-strain curves for new rope samples NS4 (dry: black line) as well as NS5 and NS6 (after immersion in tap and salt water: blue and red lines respectively) subjected to a single bedding-in cycle of load set LS4. Load-to-failure curves for the saturated samples as also shown. Measured loads are expressed as a percentage of the rope MBL $(F *=F / M B L)$. (For interpretation of the references to colour in this figure legend, the reader is referred to the online version of this paper.) 